\title{
MOROS Y CRISTIANOS EN LA VIDA COTIDIANA: ¿HISTORIA DE UNA REPRESION SISTEMATICA O DE UNA CONVIVENCIA FRUSTRADA? (*)
}

\author{
Santiago LA PARRA LOPEZ
}

\author{
0.-NUEVOS ENFOQUES EN UNA VIEJA HISTORIOGRAFIA \\ (BREVE ESTADO DE LA CUESTION)
}

\section{1.- Dos hitos historiográficos: 1901 y la década 1950.}

Dentro de la amplia producción historiográfica sobre la presencia musulmana en nuestras tierras -objeto ya de varios estudios acerca de cómo ha ido evolucionando su tratamiento y alguna recopilación, muy útiles (1)- nosotros destacaríamos dos momentos especialmente significativos: 1901, como un punto de llegada, a modo de síntesis, de la producción anterior; y la década de los años 50, que podemos considerar, por

( ${ }^{*}$ Después de entregado este artículo para su publicación, han aparecido ya otros trabajos (a alguno de los cuales, además, nos hemos referido en nuestro texto) sobre los que nos parece que debemos hacer mención expresa aquí. Es el caso, por ejemplo, del S. DE TAPIA SÁNCHEZ: La comunidad morisca de Ávila (Salamanca, 1991) o de la obra de H.Ch.LEA, cuya edición ha sido presentada por R. BENITEZ SÁNCHEZ-BLANCO, destacándose en ella dos aspectos: primero, el ímprobo trabajo de revisión y, en su caso, corrección una a una de las notas a pie de página de la versión original (lo que exige, entre otras consideraciones, un conocimiento exhaustivo de las fuentes); $y$, en segundo lugar, el que en este Estudio Preliminar se cuestionen por vez primera las diferencias en el tratamiento del tema morisco (que hasta ahora veniamos admitiendo) entre la historiografía considerada conservadora (desde Menéndez Pelayo hasta $P$. Boronat) y la de carácter más liberal (Janer, Muñoz y Gavaria, V. Boix...).Es una interpretación, que pudiera parecer mixtificadora, pero sobre la que cabrá reflexionar.

Igualmente quisiéramos dejar constancia de la aparición reciente de El problema morisco (desde otras laderas) de F. MÁRQUEZ VILLANUEVA (Ed. Libertarias Prodhufi, Madrid, 1991), así como de la línea de investigación que desarrolla el profesor A. CARMONA GONZÁLEZ (Cfr. por ejemplo, "Aportación al estudio del contrato matrimonial en el occidente musulmán", Actas del XV Congreso de la UEAI, Utrecht, 1990, en prensa) pues en ambos casos, y desde perspectivas hoy distintas (crítica literaria y jurisprudencia, respectivamente) el enfoque del tema, su tratamiento y conclusiones están en perfecta sintonia con lo que hemos querido explicar y defender en nuestro texto presente. 
contra, como punto de partida. Es fácil advertir que ese primer hito vendría señalado por la aparición en tal año de la obra de mosén Pascual Boronat y Barrachina, por una parte, y la del estadounidense Henry Charles Lea, por otra (2), mientras en la década de 1950 -el segundo hito remarcado- coinciden los conocidos estudios de Joan Reglá (quien empieza a ocuparse del tema en 1953), Tulio Halperin-Donghi (1955-1957), el de Julio Caro Baroja sobre los moriscos granadinos (1957) y la Géographie... de Henri Lapeyre (1959).

1901, punto de llegada.- La obra de Boronat (prologada por M.Danvila y Collado) entendemos que sigue la línea -y la culmina- de la historiografía más conservadora del Ochocientos, representada por el propio Danvila, Roque Chabás, Menéndez Pelayo... (3), quienes no sólo justifican sino que alaban la expulsión de los moriscos, pues entienden que la medida de Felipe III significaba el final "lógico" y necesario de la empresa iniciada por Don Pelayo y jalonada por los Reyes Católicos. En cuanto al aspecto más concreto que nos ocupa aquí ahora -las relaciones entre ambas comunidades, morisca y cristiana- la vehemencia de Menéndez Pelayo no deja lugar a dudas sobre su punto de vista: se refiere a los moriscos como "perversos españoles, enemigos domésticos, auxiliares natos de toda invasión extranjera" y, en fin, "raza inasimilable", de manera que su expulsión "...la tengo por cumplimiento forzoso de una ley histórica y sólo es de lamentar lo que tardó en hacerse"; acaba minimizando sus negativas consecuencias económicas, para celebrarla "como triunfo de la unidad de la raza, de la unidad de religión, de lengua y de costumbres" (4).

Este punto de vista "moriscófobo" -por resumirlo en una palabra- conecta perfectamente con las opiniones de los coetáneos, en especial la del Padre Jaime Bleda (a propósito de los valencianos) o la de Pedro Aznar Cardona (sobre los aragoneses), antes que con la del extremeño Pedro de Valencia, quien -como excepción- se mostraba contrario a la expulsión...

Muy distinta (digamos "moriscófila") resulta, en cambio, la actitud al respecto de los historiadores liberales decimonónicos como Florencio Janer, José Muñoz y Gaviria, Matías Sangrador y Vítores o Vicente Boix... (5), representantes de la línea de pensamiento que vendría a culminar en la obra de Henry Charles Lea (Philadelphia, 1901). Se muestran estos otros autores, en general, más proclives a "entender" que a "condenar" a los moriscos y alaban su laboriosidad; admiran la gestión conciliadora del arzobispo Fr. Hernando de Talavera en Granada y critican sin paliativos la de Cisneros por represora; no ocultan su profunda antipatía hacia el duque de Lerma ni el carácter pusilánime del monarca, e insisten en las negativas consecuencias económicas que comportó la expulsión (aún de manera exagerada, por ejemplo en cuanto a su incidencia en la despoblación de España...).

-El punto de partida de la década 1950: bajo la influencia de "Annales".- Desde estos años el tema se encauza por unos derroteros más científicos y menos "pasionales", en consonancia con los postulados de Annales; así, pues, con la pretensión de una "historia total" y "combativa", que aspira a "comprender" el pasado (Compendre el món) y no a juzgarlo, metodológicamente imprecisa y conectada con otras "ciencias humanas" (lo que permite -en expresión célebre de Pierre Nora- "ampliar el territorio 
del historiador"), por donde nos llega una Geografia de la España morisca o el punto de vista al respecto de un antropólogo (Caro Baroja), quien añade un subtítulo a su obra sobre Los Moriscos del Reino de Granada muy acorde con los postulados de esta escuela: Ensayo de Historia Social.

La relación cristianos-moriscos se entiende ahora como un conflicto nacional (Halperin-Donghi) o "de civilizaciones" (Braudel), término éste menos polémico añadido al título de la revista francesa fundada por Bloch y Lefebvre; es decir, dos mundos cerrados, yuxtapuestos, con caractarísticas peculiares que los diferenciaba entre sí y los lleva a un enfrentamiento en el que acaba imponiéndose el más fuerte.

En Valencia, por donde el paso del profesor Reglá desde luego no resultó estéril, se profundizará, sobre todo, en las consecuencias de la expulsión - desde la nueva distribución de la tierra (A.Bataller) a las características demográficas del proceso repoblador (Torres Morera) o el análisis de las condiciones establecidas en las cartas-pueblas (Císcar) - con lo que el período anterior a 1609, en donde se entronca la cuestión que queremos abordar aquí, queda bajo muchas sombras (6).

Precisamente es ése un terreno en el que las aportaciones de los arabistas resultan de un especial interés (como demuestran los trabajos de M. de Epalza, A. Labarta, C.Barceló Torres, D. Bramon...), cuyas transcripciones de documentos aljamiados, además, ponen a disposición del historiador una información imprescindible que, de otra suerte, le resultaría inasequible no conociendo el árabe (7). Y es fundamental, por cierto, insistir en enfocar el tema también desde este lado y no sólo desde la perspectiva cristiana, como se ha hecho hasta ahora casi siempre, aunque con excepciones tan notables como la investigación de Louis Cardaillac sobre el aspecto religioso del enfrentamiento (8).

El tratamiento de la cuestión, pues, evolucionará en paralelo a los nuevos rumbos que va tomado la escuela francesa de referencia, hasta arribar a la nouvelle histoire: de aquella "historia total" se ha pasado a hablar de una "historia en migajas" (9), y del enfoque global dado hasta ahora a la cuestión morisca a un "desmenuzamiento" de ésta en aspectos más diversos. Ejemplos eximios de esa apertura temática y de su nuevo tratamiento, que nos sitúan en la línea de las tendencias historiográficas actuales, podemos muy bien hallarlos en la obra del profesor Bernard Vincent (centrada, sobre todo, en los moriscos andaluces) (10) o, también, en las investigaciones al uso basadas en fuentes inquisitoriales (11).

\section{2.- Tendencias actuales: la historia fragmentada.}

La actual tendencia a la diversificación creemos que enriquece extraordinariamente a la Historia, en cuanto que le aporta dimensiones nuevas, temática y metodológicamente. El historiador "invade" terrenos que se suponían exclusivos de la antropología, sociología, incluso la psicología, filosofía o la crítica literaria... y adopta métodos propios de éstas y otras ciencias, como demuestran, por ejemplo, los avances en la demografía histórica y la complejidad de sus métodos actuales. Pero esta fragmentación no es sólo temática (concretada en la llamada "historia de las mentalidades"), sino tam- 
bién de perspectiva, acorde con la "historia local", ciertamente más limitada, pero, por eso mismo, hace posible una observación más minuciosa y ese sincretismo temático al que nos referíamos (12); lo cual permite precisamente, por ejemplo, acceder a la cotidianeidad en el pasado (¿podría tratarse desde otra óptica?)... que es, sin duda, uno de los temas más en boga dentro de la producción historiográfica actual.

Pero este punto de vista nuestro, al parecer, no coincide con otras opiniones más pesimistas, aunque mucho más autorizadas: "en cuanto a la producción española -escribe, por ejemplo, García Arenal al respecto-, está demasiado limitada por este nuevo interés, tan condicionado por la situación política actual, por lo local, y demasiado falta de nuevos planteamientos y ópticas generales, pobre, en fin, de ideas nuevas" (13).

Naturalmente disentimos de este juicio, aunque deberíamos empezar por averiguar a qué se refiere exactamente ahí la Dra. García-Arenal con "lo local", pues estamos convencidos de que no es, desde luego, al Valladolid de Bennassar o al Montaillou de E. Le Roy Ladurie, ni tampoco -nos consta- a la Almería morisca de Nicolás Cabrillana o al Condado de Casares de R.Benítez Sánchez-Blanco, obras éstas expresamente elogiadas - con toda justicia- en ese mismo trabajo de dicha autora. Por otra parte, no parece necesario tener que insistir ahora en la diferencia entre lo que se entiende hoy por "historia local" (14) y lo que ha sido (y no negamos que pueda seguir dándose en algún caso) "historia localista" o simplemente "pueblerina", a cargo de eruditos locales aficionados, de la que no se puede decir siempre que sea ni positivista...

En cuanto a la "ausencia de planteamientos nuevos" y esa "pobreza de ideas" que ahí se denuncian, es casi una acusación que podríamos volver del revés, contra los estudios generales, si ello no supusiera incurrir en una generalización igualmente abusiva e injusta, y no lo haremos. Pero sí podemos plantearnos, por ejemplo, cómo afrontar el análisis de la demografía: ¿basándonos exclusivamente (...como hasta ahora) en los censos generales conocidos y en los testimonios de los coetáneos, o intentándolo a partir de otras fuentes alternativas, como los quinque libri sobre todo -allí donde los haya y el párroco permita su consulta- u otras menos conocidas (15)?, ¿debemos seguir renunciando al estudio de la familia morisca, como ha denunciado el profesor Chacón (16)?; ¿cómo analizar las dotes o las herencias, transmisiones u otro tipo de contratos que nos acercan a la realidad cotidiana del morisco, si no es trabajando los protocolos notariales y cómo hacerlo de una manera general?; ¿cómo calibrar la importancia complementaria que pudieran llegar a tener las actividades económicas extraagrarias en la renta de la población morisca?; ¿qué decir de la ocupación del suelo -urbano o de labor- prescindiendo de la documentación municipal, como los libros de peita, tachas sobre regadío, pleitos vecinales, etc...?; ¿no es cierto que los libros judiciales -y hay también una justicia local- nos arrojarían mucha luz acerca de la verdadera forma de vida de esta minoría, que no podemos seguir pensando que se ajustara en la realidad a todo lo dispuesto en las prescripciones islámicas o la legislación cristiana represiva?... 
Parece claro, en fin, que quinque libri, protocolos notariales, procesos judiciales de todo tipo (incluyendo los inquisitoriales), acuerdos y ordenanzas municipales, etc... son fuentes no diremos inéditas, desde luego, en nuestra historiografía, pero sí de una relativamente reciente aplicación sistemática y sobre las que debemos seguir insistiendo mucho más, pues estamos convencidos de que, a partir de estas monografías locales (y ya vamos contando con algunas muy interesantes), se llegará a modificar y rectificar algunas (puede que muchas) de las explicaciones que hoy todavía se admiten como ciertas sobre los moriscos y las consecuencias de su expulsión.

Por lo demás, a nosotros nos parece que resulta muy difícil el manejar este tipo de información pretendiendo abarcar ámbitos muy generales... aún admitiendo gran pericia en el dominio de la informática (lo que facilitaría, en todo caso, la elaboración de largas series y muchas estadísticas, pero no nos ahorrará las preguntas que el historiador debe formularse ante su documentación a título de hipótesis ni las conclusiones que quepa obtener).

Cuando se procede así, naturalmente los resultados no son en absoluto desdeñables (antes bien, se hacen imprescindibles) y a las pruebas concretas nos remitimos. Empezando por lo que se está estudiando en estos momentos fuera de Valencia, pensemos, por ejemplo, en las investigaciones de Serafín de Tapia sobre la aljama de Avila (la más numerosa de Castilla-León) (17); las de Pascual Ortega Pérez sobre los moriscos del Bajo Ebro (18); los resultados del seminario, en el CSIC de Barcelona que dirige la Dra. Ferrer i Mallol, sobre los mudéjares de la Corona de Aragón (19); o en la tarea de recuperación que lleva a cabo el Departamaneto de Historia Moderna de la Universidad de Zaragoza sobre los moriscos aragoneses, que -pese a su importancia cuantitativa- era un tema bastante abandonado hasta ahora (20).

En el caso concreto de Valencia, donde la cuestión adquiere una especial relevancia, como se sabe, por concentrarse aquí la mayor parte de los moriscos, se da la circunstancia de que hemos dispuesto primero de las visiones generales de conjunto $\mathrm{y}$, por lo tanto, sin poder tener en cuenta las peculiaridades y matices "locales", que son, sin duda, fundamentales. E insistimos, una vez más, en que con ello no nos referimos solamente a características propias y exclusivas de un determinado ámbito geográfico, más o menos reducido, sino a otras consideraciones nuevas (nacidas al socaire de esas fuentes hasta ahora infraexplotadas -si no vírgenes-) la generalización o excepcionalidad de las cuales sólo podrá ser dictaminada cuando dispongamos de más monografías de este tipo, para poder comparar y contrastar las conclusiones respectivas. Y no se piense que hablamos pensando en nimiedades anecdóticas, cuando nosotros mismos hemos propuesto, por ejemplo, que se considere, comprobándolo empíricamente, el grado de aplicación en cada lugar de las cartas-pueblas posteriores a 1609 antes de sacar conclusiones que, sin esta prevención, resultarán seguramente precipitadas y poco realistas.

Pero, de nuevo, la mejor prueba del interés que pueden tener este tipo de investigaciones la hallamos en los trabajos hechos realidad, con los que poco a poco se va completando una "geografía morisca del país valenciano", desde la fronteriza Orihuela has- 
ta el desconocido ducado de Segorbe, pasando por Elche, el condado de Cocentaina y tierras de La Marina alicantina, la ubérrima huerta de Gandía y condado de Oliva, la Valldigna, Alzira, Corbera, Carlet... (21).

A partir de aquí estamos en condiciones de empezar a replantearnos -aún de manera provisional todavía- cómo pudieran ser efectivamente las relaciones entre moriscos y cristianos en la vida cotidiana... porque las disposiciones oficiales al respecto (tanto islámicas como cristianas) ya las conocíamos. Ahora, desde la nueva perspectiva que nos ofrecen estas investigaciones más recientes, se trata de intentar analizar si ciertamente aquella dualidad cultural implicaba una situación social discriminatoria para con los que habían sido primero vencidos, luego bautizados $\mathrm{y}$, al final, expulsados por orden de Felipe III. Es decir, ¿hasta qué punto se hizo imposible a lo largo de estos siglos una convivencia entre vecinos... porque los unos rezaban a Alá y los otros a Cristo?; ¿o había algo más que eso?... que son, pues, dos cuestiones...

\section{I.- CONVIVENCIA-TOLERANCIA O REPRESION-DISCRIMINACION: DE LA POLEMICA A LA BUSQUEDA DE LA COHERENCIA.}

Respecto a la primera de esas dos preguntas anteriores, hallamos, de entrada, una respuesta tajante por parte de Caro Baroja: "Pecaría de ligero... -escribe en su "ensayo" sobre los moriscos granadinos- el que describiera la situación creada entre cristianos viejos y moriscos, ya a comienzos del s. XVI, como una simple dicotomía, como un estado de convivencia en el que el oprimido y el opresor vivían opuestos en todo. No. Si los moriscos, como tales, hubieran tenido a la totalidad de los cristianos en contra, no hubieran podido aguantar lo que aguantaron sobre el territorio español" (22). Podría replicarse que ciertamente "la totalidad de los cristianos" son demasiados (aún para odiar al unísono) y que el argumento que se esgrime aquí se remite al resultado empírico y no a cuestiones de fondo. Pero también Domínguez Ortiz y B.Vincent, a propósito de la rebelión de las Alpujarras, observan que nace en la montaña y se expande hacia el llano, aunque no deja de ser un movimiento esencialmente rural pues "los moriscos de las ciudades no participaron activamente ni los de las llanuras estrechamente relacionadas con ellas", admitiendo como "probable que en bastantes sectores la "convivencia", facilitada por múltiples relaciones, era una realidad"; tampoco la secunda el Albaicín (pese a las tentativas en este sentido de Farax Aben Farax) porque "los moriscos del Albaicín llevaban decenas de años conviviendo con los cristianos" (23), y se incluye asimismo, más adelante, un capítulo sobre "La difícil convivencia". Nosotros mismos, en fin, hemos sugerido que la expulsión de los moriscos supondría en el ducado de Gandía "la ruptura de una convivencia" (vid. nota 21).

Todo ello, pues, choca en principio con aquellas otras interpretaciones que ven la relación entre cristianos y moriscos como un "conflicto nacional...", un "enfrentamiento polémico..." o bajo el prisma, aún más explícito "a priori", de lo que da a entender el subtítulo de la obra de $M^{\text {a }}$ Teresa Ferrer i Mallol: Els sarraïns de la Corona Catalano-Aragonesa en el segle XIV. Segregació i discriminació (24). Empero, conviene no dejarse llevar apresuradamente por esa apostilla añadida al título -como insisti- 
remos más adelante- pues "la convivència de totes tres comunitats -quiere precisar la autora, refiriéndose a judíos, moros y cristianos en la península Ibérica durante la Edad Media- es basava en la segregació i en el respecte a l'organització pròpia de cadascuna..." (25).

\section{1.- "Continuismo" $y$ "rupturismo" en la historia medieval valenciana.}

Al hilo de estas opiniones encontradas, empiezan a hacérsenos cada vez más próximos los ecos lejanos de la polémica entre Sánchez Albornoz y Américo Castro (26)... y, sobre todo, los más cercanos a nosotros de la que enfrenta a "rupturistas" y "continuistas" sobre la historia medieval valenciana. Pero no insistiremos aquí acerca de si la "esencia" de España se labra en la lucha contra el moro a lo largo de ocho siglos de Reconquista ("Santiago hechura de España y no España obra de Santiago", leemos en España, un enigma histórico) o si, por el contrario, ésta es el resultado de una larga "convivencia" entre esas tres culturas que terminaría con la imposición de la cristiana, pero con rasgos indelebles de las otras dos, que es lo que le confiere su verdadera peculiaridad...

Sin embargo, sí parece oportuno, en cambio, que nos detengamos un momento en la controversia más actual en torno al significado histórico de la invasión y presencia musulmana en tierras valencianas, como antecedente inmediato y punto de partida de la cuestión que aquí abordamos. Así, la explicación "continuista" tiende a minimizar las consecuencias de esa invasión, como también las de la conquista cristiana del siglo XIII, reduciendo sus efectos poco menos que a un cambio en la casta dirigente y en el aspecto religioso pero sin afectar fundamentalmente a las estructuras sociales ni económicas hispanovisigodas: "insistimos en admitir -escribe F.Roca Traver en este sentido- que el orden anterior a la conquista cristiana, en todo lo relativo al agro varía bien poco. Ni hubo gran cambio con la invasión sarracena, ni debió haberlos con la conquista aragonesa: lo pre-jaimino fue respetado por la sencilla razón de que era interés general el que así fuera" (27). Para apoyar esta idea se hace hincapié en la reivindicación del origen romano -que no árabe- del regadío valenciano y, en efecto, las investigaciones arqueológicas lo ratifican (28); pero ello no puede hacernos olvidar las aportaciones fundamentales de los árabes en la ampliación de la red de riegos y la introducción de técnicas y cultivos nuevos de extraordinaria importancia -como ha demostrado Thomas F. Glick- de modo que resulta poco fundada la hipótesis de Roca-Traver, ahí mismo, suponiendo que los cultivos valencianos del s. XIII vendrían a ser los mismos que los de la época romana. Y resultan mucho más descabelladas aún las conclusiones lingüísticas que se pretenden derivar de esta teoría, que van mucho más allá de lo que hoy por hoy alcanza la Filología Románica y aconseja el rigor científico.

La expresión más radica: de semejante punto de vista (próximo a las tesis de Menéndez Pidal o Sánchez Albornoz, antes que a las de Castro) podría ser la infundada obra de Ignacio Olagüe: Les Arabes n'ont jamais envahi l'Espagne (29), pero lo hallamos también ya en F.J. Simonet (Historia de los Mozárabes en España, Madrid, 1897-1903), J. Ribera y Tarragó (Disertaciones y Opúsculos, Madrid, 1928) o en la tan 
discutida obra Orígenes del reino de Valencia, cuestiones cronológicas sobre su reconquista (Valencia, 1975) del profesor Antonio Ubieto, aparte de en otros autores que escriben sobre ello como meros aficionados

Frente a esta teoría "continuista", Pierre Guichard viene insistiendo en la reivindicación de "las dos rupturas fundamentales de la invasión musulmana a comienzos del siglo VIII y de la conquista cristiana del s. XIII", no ya sólo por lo que se refiere también, claro, a los aspectos estructurales, sino incluso aún más allá: "la conquista musulmana -concluye este autor- tuvo como consecuencia una aportación étnica mucho más importante de lo que se ha admitido generalmente, constituida en su mayor parte por elementos beréberes magrebíes" (30); y aduce como prueba relevante de su tesis la pretendida conexión directa entre las "villae" romanas y las alquerías musulmanas, que entiende infundada, dado que como demuestra la toponimia las "alquerías" son de origen árabe y, consecuentemente, posteriores al 711.

A propósito de la conquista en el s. XIII se entiende ahora que aquella otra teoría "continuista" y "tradicional" se convierte en "estática" (en tanto que niega esta segunda ruptura) y "optimista" por el juicio benévolo que merece a sus seguidores la actitud de los nuevos dominadores cristianos para con los moros vencidos: "no debemos admitir, ni por un momento -vuelve a escribir Roca Traver-, aquella intolerancia e incomprensión hacia la raza vencida que en tantas ocasiones hemos podido leer en tantas monografías", pues "los mudéjares valencianos disfrutaron en todo momento de una libertad de movimiento que difícilmente encontrará parangón en ninguna comarca de la Península... (y) en ningún momento fueron objeto de incomprensión o intolerancia"; todo lo cual se atribuye al tacto político de Jaime I, reflejado en la magnanimidad con que se redactan las capitulaciones de rendición, donde se "...ofrecían amplias perspectivas de vida a los sometidos..." (31). Frente a esta visión, ciertamente un tanto id́lica, P. Guichard -que involucra en ella al P. Robert I. Burns (32)- vuelve a recordarnos que "en realidad, los escasos 'tratados de capitulación' o cartas pueblas de la época de la conquista cuyo texto se ha conservado hasta nuestros días, sólo pueden servir para estudiar la situación de los musulmanes durante unos pocos años, y en ningún modo para definir las condiciones de existencia de los mudéjares valencianos durante todo el siglo XIII, y menos aún en épocas posteriores" (33). La sublevación de Al-Azrâq primero (1247-1258) y los sucesos de 1276-1278, después, señalarían el final de esa etapa condescendiente por intereses poblacionales para con los mudéjares, lo cual es ratificado también por E. Guinot -buen conocedor de las cartas pueblas medievales precisamente- aún en un ámbito tan alejado del epicentro de la revuelta de mediados del s.XIII como es Castellón (34).

\section{2.- Los retos de la coherencia.}

A nosotros, que no solamente no tenemos inconveniente alguno en admitir esa doble ruptura sino que añadiríamos la evidencia de una tercera en 1609-1614, nos plantean muchas dudas, sin embargo, algunas explicaciones al uso sobre las relaciones entre moros y cristianos a lo largo de esos casi cuatrocientos años que transcurren des- 
de la conquista a la expulsión. Un período de tiempo ciertamente muy largo, difícil de abarcar, por tanto, con una sola mirada (máxime habida cuenta la precariedad de estudios sobre los mudéjares valencianos que denunciábamos antes) y que, por otra parte, tampoco cabe pensar que evolucione de una manera lineal y uniforme, cronológica ni geográficamente: es claro que la cuestión adquiere relevancia especial en Granada (hasta 1571) y, sobre todo, en Valencia y Aragón (por razón del número de los habitantes musulmanes que permanecen aquí), así como que el bautismo forzoso del primer cuarto del Quinientos introduce un elemento nuevo y fundamental: los "nuevamente convertidos de moros" ya no son infieles sino apóstatas y, como tales, entran en la jurisdicción del Santo Oficio.

Esa conversión forzada tendría en Aragón -según $M^{a}$ Luisa Ledesma Rubio- otro tipo de consecuencias añadidas por cuanto la pacífica convivencia conocida aquí, "durante más de cuatro siglos", queda truncada ahora de manera definitiva, hasta desembocar en la expulsión (35). Se apunta así, pues, una situación para estos mudéjares que sería sustancialmente diferente de aquella otra, bajo el signo de la "segregació $i$ discriminació", que sugiere $\mathrm{M}^{\mathrm{a}}$ Teresa Ferrer en su libro ya reseñado sobre "els sarraïns" de la Corona de Aragón en el siglo XIV, o Blanca Basáñez, discípula de la Dra. Ferrer, sobre el caso particular de la aljama de Huesca (36).

Pero conviene, decíamos, no sacar conclusiones precipitadas a partir del título de la obra de $\mathrm{M}^{\mathrm{a}}$ Teresa Ferrer, en donde la abrumadora cantidad de información manejada es la mejor prueba de que un problema tan complejo como éste no puede tener una respuesta simple. El estudio se divide en dos partes, más un copioso apéndice documental: la primera de ellas dedicada a "la segregació dels sarraïns" ("en la residència i en les activitats socials", la "segregació sexual" y en "la imposició de distintius") y la segunda a "la llibertat religiosa dels sarraïns". El procedimiento seguido consiste en comenzar por hacerse eco de las restricciones legales que pesaban sobre esta población (desde su reclusión en arrabales, hasta la imposición de determinados signos externos que los distinguiera, pasando por la limitación de sus movimientos, etc...) y, en este sentido, es evidente el trato discriminatorio.

Pero otra cosa, muy diferente, resulta el grado de cumplimiento de esas normas y el rigor efectivo puesto en su observancia cotidiana, tal y como demuestra ese ingente acopio de documentación probatoria, pues con bastante frecuencia hallamos que “...alguns monarques oblidaren les normes de segregació si convenia als interessos de la Corona" (37). Y, así, por ejemplo: en 1304 Juan II expulsa a las prostitutas cristianas de la morería de Valencia... y a mediados de siglo ya estaban ahí de nuevo; la pena capital con que se castigaban los contactos sexuales entre moro y cristiana (aunque ésta fuera prostituta) ...no fue efectiva en la práctica (p.: 17); “... no pas a tot arreu hi hagué diligència en l'execució de les noves disposicions" sobre el peinado que debían llevar los moros... por más que en Valencia contravenir esta norma había sido castigado con la pena capital por Pedro El Ceremonioso en 1341, aunque sólo cuatro años después la había rebajado a 60 "sous" de multa (p.: 43-44); en las Cortes Generales de Monzón de 1390 se aprueba que moros y moras lleven una infamante cinta amarilla en el brazo derecho -roja, si el vestido era amarillo-... pero el 21 de enero del año 
siguiente, 1391, Juan I suspende la aplicación de este acuerdo, que volvería a entrar en vigor, sólo durante unos meses, en 1397 (pp.: 56-57); “...la prohibició de la crida de la salà fon observada a cops amb excés de zel i a cops amb molta condescendència" (p.: 90), e incluso a finales de siglo el monarca se niega a prohibir el toque del anafil moro para llamar a la oración en algunos lugares de Valencia, aunque sonaba inmediatamente después de las campanas para misa, porque tocar la trompeta "no és senyal desonest" (p.: 93-94); no obstante la limitación de movimientos que pesaba sobre los mudéjares, ello no les impedía continuar con sus actividades mercantiles, yendo de uno a otro sitio, ni tampoco las peregrinaciones a lugares tenidos como santos. Uno de estos centros de peregrinación más importantes era Adzaneta (Vall de Guadalest) en donde acudían hasta de Granada para venerar los restos de un santón moro; y aún el santuario se reconstruiría en tiempos del Almirante de Aragón, don Sancho de Cardona (quien, como se sabe, acabaría siendo procesado por la Inquisición, entre otras cosas, por facilitar salvoconductos a moriscos para huir a Berbería) (p.: 95-100).

Por el otro lado, en fin, es bien conocida la frecuencia con la que los moros valencianos transgredían la norma coránica que les prohibe beber alcohol (lo que no pasa desapercibido, claro, a $\mathrm{M}^{\mathrm{a}}$ Teresa Ferrer)... y, en definitiva, como escribe B.Basáñez sobre Huesca: "la convivencia entre cristianos, sarracenos y judíos se hizo patente también en momentos de esparcimiento. Las tahurerías o casas de juego fueron frecuentadas por miembros de las tres comunidades, aunque se daba la paradoja de que a los moros se lo prohibía su religión y a los cristianos la ley. Sin embargo, tanto unos como otros prescindieron de la legislación humana y divina, y jugaron siempre que pudieron" (38). Ante esta casuística que contradice, o al menos hace compleja, la aplicación en la vida real de las normas restrictivas para con los musulmanes, nos ha parecido que puede resultar clarificador, y mucho más coherente, enfocar la cuestión a partir de una doble diferenciación de planos: el "institucional y secular de la represión", por una parte, del "local y cotidiano", por otra, en el seno del cual nosotros sí creemos que se da una verdadera convivencia.

\section{II.- UNA REPRESION INSTITUCIONAL Y SECULAR.}

\section{1.- Los límites de la represión.}

No parece razonable negar, si quiera sea en este nivel al que nos referimos nosotros, la evidencia histórica de la represión para con los musulmanes. Frente a ella, se ha hablado, por una parte, de la taqiyya ("precaución") y kitmân ("discreción") como actitudes previstas y avaladas por el Islam para preservar la vida del creyente cuando ésta se pone en peligro por causa de su fe. Por otra, a menudo se ha contrapuesto la intransigencia cristiana con la tolerancia observada en Al-Andalus, resultado de la recomendación coránica de respeto a los monoteístas --"gentes del Libro" (Ahl al-Kitab)-, así como por razones fiscales (al pesar sobre los cristianos un tributo añadido -djizya-) (39).

Ante ello conviene recordar, primero, que tales actitudes de rechazo no eran unilaterales: los moriscos valencianos presentan un alto grado de cohesión como grupo dife- 
renciado, lo que les permite mantener viva la llama de la tradición (mientras en otros lugares peninsulares se ha perdido), por razón de su número y concentración, y gracias a dos instituciones propias del "ámbito aragonés", como la "aljama" y la "aljamía" (40). L. Cardaillac nos avisa, por ejemplo, de cómo algunos moriscos de Toledo mandaban a sus hijos a Valencia para aprender el árabe y, por otra parte, recoge recomendaciones como ésta (cuya transcripción hemos actualizado aquí) en uno de los manuscritos aljamiados que maneja: "El muslim que acompaña con el cristiano cuarenta días por amistad dél, si muere en estos cuarenta días, muere descreyente y va a Yahanam" (que es el infierno) (41)...

En segundo lugar, y a propósito de esa tan comentada actitud tolerante musulmana, C. Barceló alude a la existencia en Al-Andalus de algo parecido a un tribunal inquisitorial, "constituït pels cossos consultius d'alfaquís i cadis", de manera que "la persecució d'Averroes, dels mutazilins, l'expulsió dels mossàrabs, la deportació dels cordovesos del raval, les revoltes antijueves de Granada, i tants altres casos no evidencien la tolerància que la historiografia tradicional presuposa"; se hace eco también de unas ordenanzas de policía (Sevilla, s. XII) en las que se contemplaba que "deberán ser aborrecidos los cristianos y judíos y llevar un signo por el que sean conocidos, por vía de su humillación", recomendando que les fueran reservados los trabajos más serviles... (42).

El rechazo, pues, es mutuo, basado en el hecho diferencial. ¿Y cuál era realmente esa diferencia?; ¿étnica?: no solamente parece claro que no, sino que las pruebas en contra hasta se pueden recoger en retratos fotográficos (43); ¿acaso por su aspecto externo? tampoco parece que fuera así siempre y, de hecho, nos sorprende la manera cómo fueron reconocidos -según confiesan ellos- unos moriscos tragineros de Castellón que, en 1567, fueron asaltados en la costa de Tarragona por piratas berberiscos: “...els regonegueren per lo membre esser recollits", declara uno de los encausados -Martí Zeyt- en el juicio seguido para aclarar los hechos, y lo confirma su hijo -Gaspar Zeyt- explicando que los asaltantes "... a ell, confesant, com a tots los altres traginers los feren levar los saragüelles y regonegueren si y havya algú cristià vell entre aquells..." (44).

Tampoco creemos nosotros, en contra de lo que se ha sugerido, que su nivel de vida o la situación económica los pudiera distinguir por ser sensiblemente inferior (pero este punto merece ser tratado aparte), de modo que, en efecto, debemos concluir remitiendo la explicación a una cuestión de diferencias culturales (llámesele "de civilizaciones" o "nacionales"), basadas en la distinta religión. Y si -como recoge Cardaillac- “...en su nivel más bajo la cultura católica de los moriscos no es en absoluto superior a la cultura islámica de los cristianos $y$, por tanto, se hacen posibles muchos equívocos teológicos..." (45), habrá que empezar a pensar que el conflicto realmente lo alimentaban quienes sí podían leer la Biblia o el Corán..., porque, además, conocían el latín y el árabe clásico en el que estaban escritos. Fr.Nicolás del Río, nuncio inquisitorial en Valencia, sí compartía (involuntariamente) esta opinión: los alfaquís -escribía a Felipe II en junio de 1606- "son los que sustentan a toda la morisma (...) y es cierto que, quitados los alfaquines, los demás con mucha facilidad se convertirían" (46), 
como antes había dicho también el inquisidor Miranda: “...si algunos déstos [los alfaquíes] se convirtiesen y reduxesen a nuestra Religión, podrían ser muy provechosos para persuadir a la gente común porque les darían mucho crédito..." (47).

Prueba ajustada de lo acertado de estos dictámenes la podemos hallar reflejada en las dudas que asaltaban a aquel pobre morisco conquense en su lecho de muerte (a quien oímos hablando en francés aquí), que nos ponen sobre la pista de la verdadera fortaleza de la fe popular y de la profundidad de las convicciones religiosas en la gente común: el moribundo pide le sea administrada la Extremaunción, pero duda y consulta con sus hijos sobre "quelle est la véritable foi qui assure le salut, si c'est celle des Mores ou celle des Chrétiens, car il voudrait bien mourir dans la vraie religion"; ellos acaban convenciéndole de que no abjure del Islam, pues es "le chemin direct pour aller au paradis; il faut d'ailleurs venir au chevet du mourant un lettré musulman pour finir de le convaincre..." (48). Y no sería éste, desde luego, un caso excepcional ni el único conocido: "En Murcia -relata J.Blázquez, por ejemplo- (...) no había verdugo inquisitorial, pero sí lo había concejil. En 1582, lo era el morisco Miguel Hernández. Ese año fue a Lorca a ajusticiar a tres moriscos. Estando éstos en la cárcel se hicieron cristianos. Al llegar Miguel y enterarse comenzó a reprendérselo en lengua árabe...", lo cual le acabaría costando a él 200 azotes, después de ser torturado, y ocho años en galeras sin que le valiera de nada aducir que no recordaba lo sucedido pues estaría borracho (49).

Y, por supuesto, nada nos hace pensar que la fe del cristiano común fuera mucho más sólida ni estuviera más arraigada..., con lo que unos y otros se convertían en presas fáciles para la manipulación. En Granada, de hecho (y esta comprobación nos ahorrará muchas explicaciones), "el fenómeno de rechazo que sufrió la comunidad morisca por parte de los cristianos viejos no alcanzó nunca a los moriscos más encopetados. Por el contrario, como éstos asimilaron muy rápidamente la cultura mayoritaria, tuvieron derecho a todas las consideraciones" (50).

Esa religión, pues -y no otra cosa-, se convierte en una línea divisoria, en aquella "frontera interior" a la que se refirió Sebastián García Martínez, entre el "ellos-conversos" y el "nosotros-cristianos viejos", que se hace evidente, palpable para todos, por medio de los peculiares usos y costumbres que impone a sus fieles (no comen carne de cerdo, ayunan durante el Ramadán, rezan de manera diferente y celebran ritos distintos...). La explicación, maniquea, es fácil de entender: "los otros" son un peligro político, una amenaza latente para nuestra seguridad por su previsible acción quintacolumnista para con sus hermanos berberiscos (pocas veces bien documentada, sin embargo -esa colaboración interna-, para un período de tiempo tan largo) y, desde luego, una lacra religiosa, ante cuya pertinacia fracasan tanto los esfuerzos del Santo Oficio para erradicarla por la fuerza, como también la acción pastoral de los predicadores mediante la conversión. Y éstos serían precisamente los argumentos que se aducirían como justificación de la expulsión: "...para conservación y seguridad del reino" (51).

Pero permitasenos recordar que la medida no se tomó en los momentos de máxima efervescencia contrarreformista del reinado de Felipe II, ni cuando arreciaba más la 
ofensiva contra los turcos, no. La decisión la toma su hijo con el consejo de un valido omnipotente, paradigma de la corrupción política, en el momento más calmado de la política exterior de la monarquía a lo largo de todo el Seiscientos... ¿No será lógico, entonces, comenzar a preguntarse si la solución final de que son víctimas los moriscos no tenía, más que nada, el sentido de una medida ejemplarizante y como aviso hacia el interior para todo aquél -persona o grupo- que sintiera veleidades de disidencia...?; ¿no estaremos ante una manifestación de fuerza a cargo de un poder débil, que precisamente por serlo necesita presumir de lo que carece... ante un enemigo indefenso, claro...?. Aunque aquí no podemos ahora abordar con el detalle que sería necesario todos los matices de la cuestión (52), tampoco ahorraremos, siquiera un breve comentario, sobre este aspecto fundamental: la acción de inquisidores y predicadores.

\section{2.- Inquisidores y predicadores.}

Que los moriscos, por el hecho de serlo, fueron víctimas destacadas (sólo superados por los judaizantes) de la represión ejercida por la Inquisición, es un hecho innegable y en ningún momento pretendemos dar a entender otra cosa. Con todas las reservas que se quieran tomar, los números son, en este sentido, el argumento más claro y contundente. Así, ya en el Congreso de Cuenca (septiembre de 1978) presentó Jaime Contreras una primera valoración indicativa, a partir de las "relaciones de causas de fe" (en la que no se incluían los tribunales de Cuenca y Madrid), según la cual el Santo Oficio habría pronunciado un total de 49.092 condenas desde mediados del s. XVI hasta el 1700 (la bula fundacional de Sixto IV era del 1-XI-1478 y el decreto de su definitiva supresión del 15-VII-1834); de los dichos condenados, en torno al $40 \%$ lo fueron por herejía y concretamente 11.311 de éstos por islamismo, lo que significa el $23 \%$ del total (53).

Es lógico, por lo demás, que esta represión no tuviera la misma importancia cuantitativa en todos los tribunales: lógicamente resulta esporádica en los de Llerena, Logroño, o Galicia, por ejemplo; es ya más significativa en los de Murcia o Cuenca (quizá por la proximidad de los valencianos en este caso) y sistemática en los de Granada sobre todo y Valencia. En el granadino son acusadas de islamismo el 40'8\% de las 3.455 personas procesadas (habida cuenta de que falta la documentación de los primeros años, entre 1526 y 1550 ) y -lo que nos parece más significativo- eran también moriscos el $60 \%$ de los condenados en auto de fe desde 1550 a 1615 (54).

En Valencia, según establece R. García-Cárcel y lo ratifica R. Carrasco, hasta 1530 casi podríamos hablar de una época de amnistía; pero las cosas cambiarían sustancialmente a partir de 1566 (coincidiendo con el final del mandato de Valdés como Inquisidor aquí) y, sobre todo, durante las dos últimas décadas del Quinientos (después de la rebelión de las Alpujarras): hasta 1530 el número total de procesados pudieron ser -calcula García Cárcel- unos 2.354, mientras que pasan de 5.000 los encausados descle esa fecha hasta 1609; pues bien, un total de 5.500 (más del $75 \%$ ) eran conversos 
y, de éstos a a su vez, el 56'5\% moriscos y el resto judaizantes (55). Y, según conclusiones de R. Carrasco, entre 1566 y 1620 el ' 73 ' $4 \%$ del total de procesados, 86 ' $3 \%$ de los torturados y $65^{\prime} 2 \%$ de los relajados en persona fueron moriscos" (56).

No hay duda, pues, de la dureza del Santo Oficio para con los moriscos, pero igualmente que la suya no fue una actuación sistemática ni uniforme a lo largo del tiempo. ¿Cabe pensar, ante ello, que esa discontinuidad fuera una táctica deliberada del tribunal valenciano, más en contacto con el problema que se pretendía combatir?. Parece claro que no, pues la autonomía que cupiera suponerle a cada tribunal territorial sencillamente no existía. La Suprema se concibe como una institución férreamente centralizada y, consecuentemente, su actuación en Valencia también respondía a directrices de arriba; de manera que, mientras el 28 de abril de 1524 el Inquisidor General remitía desde Burgos una circular a todos los demás instándoles a intervenir contra los moriscos solamente cuando ayan cometido cosas que concluyan derechamente heregía (pidiéndoles, incluso, que dejaran en libertad a los procesados con cargos que no resultaran abrumadores) (57), el 5 de junio de 1591 las órdenes eran que a todos los nuevos convertidos, aunque sean buenos confitentes, se hechen a galeras... (58).

Pero, llegados aquí, conviene que nos preguntemos también por la propia naturaleza de la misma Institución: ¿la Inquisición "opus romanum"?. Así lo han entendido, en efecto, L. Sala Molins o H. Kamen, por ejemplo, para quien es claro, por lo visto, que "nunca se convirtió el tribunal en un instrumento de represión política" (59).

Sin embargo, no es ésta la opinión de otros autores (ni la que a nosotros nos parece más ajustada a la realidad, empezando porque era la única institución común -monarquía aparte, claro- a todos los territorios de la corona): ya en 1655 (que es cuando viene a España) al sagaz viajero A. de Brunel le llamaba la atención que la sede de todos los Consejos estuviera en el recinto del palacio real salvo éste, el de la Inquisición, a la que veía él como "una ruda medicina para aquéllos cuyo temperamento no agrada al Estado" (60). En esta misma línea, G. Dufour la define como "un organismo estatal al servicio del centralismo monárquico..." y B. Bennassar entiende igualmente "que era un instrumento de la monarquía española" y "el mejor auxiliar del Leviatán..." (61). Con lo cual, las características y el sentido de esta represión quedan mucho más claras, en perfecta consonancia con esa acción institucional y secular a la que nos referimos; de otra suerte -como, por ejemplo, relacionarla con una verdadera presión popularnos resultaría mucho más difícil de entender, pues en 1609 seguía habiendo pueblos enteros de moriscos y sus alfaquíes eran, desde luego, conocidos por todos sin que tampoco la acción pastoral de los predicadores hubiera conseguido acabar con ellos.

La Inquisición, pese a todo, no erradica el problema y la predicación no da resultados positivos en la conversión masiva de moriscos; ¿nos hallamos, entonces, ante un fracaso rotundo... o es que era éste inevitable?. Mientras para Boronat, en efecto, el resultado no podía ser otro por la obstinada tozudez de los moriscos y, con ello -que es de lo que se trata- quedaba justificada la expulsión, García Cárcel, en cambio, opina que sí pudo evitarse y M. García-Arenal que los moriscos "inasimilables no eran" (62). No insistiremos más aquí, pues así ocurrió, si en efecto la expulsión se pudo o no evi- 
tar; pero lo cierto es que, tal como se planeó y llevó a cabo la evangelización e instrucción de los moriscos, no cabría pensar en grandes éxitos... como no fuera que de lo que se trataba era precisamente de dejar patente su pertinacia y, en su caso, tranquilizar alguna conciencia.

No echamos en saco roto los esfuerzos sinceros que se hicieron para lograr la conversión (63) (desde la edición de catecismos en árabe, a la ingente labor pastoral de Tomás de Villanueva o, sobre todo -en términos cuantitativos- la del otro prelado santo, Juan de Ribera) pero son empresas que nunca gozaron de la necesaria continuidad; cuya efectividad se ve muy mermada por las diferencias entre quienes deberían haber actuado coordinadamente (Inquisición y ministerio ordinario; clero regular y secular...); la precariedad de recursos para las nuevas parroquias creadas ahora (las 100 libras con las que quiso dotarlas el Patriarca nunca llegaron a esa cantidad, al menos en la huerta de Gandía), así como la escasa preparación, intelectual y anímica, del clero secular para afrontar este cometido; y, en definitiva, porque, pese a todo, el objetivo no era la asimilación mediante la convicción sincera sino la imposición por medios punitivos de unas determinadas conductas que implicaban el rechazo de la cultura árabe (64)...O dicho con palabras del doctor Frago, quien conocía bien el problema pues era párroco de la Vall de Segó: “...estoy encargado -escribía al rey el 22 de diciembre de 1560- de una rectoría de moriscos que, con ser de doze pueblos, ni ay en ella iglesia ni altar ni hermita ni christiano viejo ni christiandad, con ser ellos ya baptizados y obligados por el mismo caso a guardar nuestra Santa ley"; denunciaba el proselitismo de los moros entre los cristianos y aseguraba que maltrataban a los predicadores, pero, igualmente, que "...se cree no haver mucho más mal en los moriscos que culpa en los superiores y particulares ministros..." (65) La vía de la instrucción, por medio de los colegios que se fundan para moriscos, no resultó tampoco más feliz ni -al hilo de lo que venimos sugiriendo- nosotros diríamos más sincera. Sencillamente, en el caso concreto del de San Sebastián de Gandía que fundara el IV duque Borja (futuro santo), estamos convencidos de que, verdaderamente, no se levantó con ánimo de instruir a estos niños; de hecho no llegó a asistir ninguno y resulta un tanto sospechoso que sólo al cabo de unos meses de erigido el Colegio, su fundador consiguiera la bula que lo convertía en Universidad: ¿una Universidad para moriscos, regentada por la Compañía de Jesús? No parece lo más lógico ni resulta convincente (66).

El problema, en fin, estaba claro y el viejo Zenequi, morisco de Beniopa, lo resumió con sencillez pero acertadamente: consistía simplemente en que él no sería buen cristiano, como un cristiano no sería buen moro (67). Algunos dirigentes religiosos, sin embargo, quizá sea cierto que no lo podían entender; los políticos no lo querían entender porque no les interesaba (o sea, todo lo contrario de los señores de moriscos, los más "comprensivos") y al pueblo llano esto sencillamente no le debía preocupar demasiado, pues, entre otras cosas, siempre había sido así hasta entonces y otras cuestiones más perentorias les debían acuciar más... 


\section{III.- EL PLANO LOCAL Y COTIDIANO DE LA CONVIVENCIA.}

\section{1.- Rasgos de una convivencia.}

Hemos hablado hasta aquí de los nuevos enfoques sobre esta cuestión y de la necesidad de monografías locales para una observación más minuciosa. Uno de los frutos más notables de esta forma de proceder se refiere precisamente a los aspectos cotidianos de la compleja relación entre ambas comunidades, estudiándola a través de fuentes poco explotadas hasta ahora. Desde esta perspectiva, no cabe duda que hallamos muchos rasgos de una verdadera convivencia.

En la fronteriza Murcia, por ejemplo, el hecho parece claro, así como que este tipo de relaciones cordiales se verían muy afectadas tras la revuelta alpujarreña: "la guerra granadina significa -escribe F. Chacón- el principio del fin de la fase de integración y un nuevo recrudecimiento de las actitudes rigurosas y de rechazo" (68). No obstante, estos mismos moriscos granadinos serían muy bien acogidos en Orihuela ciudad (en el resto de su Gobernación, en efecto, las tensiones se incrementan), hasta el punto de que "el consell' [oriolano] toleraba -cuando no alentaba- una inmigración clandestina severamente penada por las leyes regnícolas"; en 1586 este mismo organismo municipal se opone a que sean expulsados y aún en 1597 solicitará autorización para traer hasta 500 familias nuevas de estos moros, dada su experiencia en los trabajos sederos y hortícolas, quienes -por lo demás- "exteriormente no se distinguen en cuanto a lenguaje, indumentaria y costumbres de la masa cristiana entre la que viven repartidos, aunque no diluidos", incluso asisten los domingos a misa y, en definitiva, "vivían en buena armonía con los cristianos viejos" (69).

En el estudio de Ferrán Garcia-Oliver sobre la Valldigna, área de intensa población musulmana, se multiplican las muestras de este tipo de cordiales relaciones cotidianas (sin que, por ello, aquella represión institucionalizada sea ajena). Así, por ejemplo, "una nit de gener de 1499, fra Joan Sahoner, monjo convers que exercia aleshores de col-lector, es presentà sobtadament en casa Jaume Conexo. Joan Cruanyes, amic del missatge Conexo que s'hi hostjava ‘agué temor no vingués per pendre Çahat Glavyet, moro de la Hombria, per algun deute de senyor; e de fet, cuytadament, devallà bayx, on dormia lo dit moro, e féu-lo amagar"" (70).

En Gandía, las festividades más solemnes -incluida, desde luego, la procesión del Corpus- se acompañaban con música a cargo de moriscos: en 1487 la "vila" contrata a Eça, "moro de la moreria de Gandia", para tocar en la procesión del Corpus; en 1532 a Carmidi "y a sos companyons jutglars"; en 1597 y 1601 a la compañía de Frances Buquet y, en 1604, "Gaspar Suleymen, nou convertit del arraval de la vila de Murla, atrobat en la vila de Gandia (...) promet el Justícia y Jurats de la vila de Gandia (...) que sonarà en la dita vila de Gandia ab dolçayna y tabals y trompeta en les festes del Corpus Xristi y octava de aquell y lo dia de la Verge Maria de agost, pagant-li lo salari que dita vila de Gandia li sol y acostuma pagar..." (71). Curiosamente, para traer la "bova" que se esparcía por las calles en esta festividad también se contrataba siempre a moriscos y, en concreto, a los de Alcodar, un pequeño lugar al norte de Gandía que quedaría despoblado tras 1609 . 
En los lugares de la huerta de Gandía, cuya población (salvo en Gandía-"vila") prácticamente toda era conversa, los propios moriscos son, en tanto que "jurats" de sus poblaciones respectivas, los administradores de las rentas de esas iglesias: en 1602 hallamos a Tomás Pardalet en Bellreguard o a F. Barbenes en Benipeixcar como alter ex administratoribus fructuum, redditum et emolumentorum novae ecclesiae supra dicti loci; en 1597 el clavario de la iglesia de Real es el morisco Miquel de Funes y, ese mismo año, en Almoines, Gaspar Quermet y Miquel Mincar son los administratores terrarum, fructuum,(...) ecclesiae predicti loci y, como tales, arriendan las tierras de la iglesia a varios moriscos (Martino Burquet, Gaspar Morit, Vicente Abes y F. Xagunti) en lotes distintos respectivamente y siempre por 4 años (72).

Y no es eso sólo; a veces los párrocos necesitan de su testimonio para justificar los servicios prestados en la parroquia y poder percibir los emolumentos correspondientes: el 19 de noviembre de 1603, por ejemplo (y no es el único caso que hemos podido comprobar) a instancia de Joan Cots -párroco de Alcodar y Beniopa- el notario B. Deusa expide certificado de su dedicación pastoral en ambas parroquias desde febrero al 26 de octubre pasado; para ello, el notario recaba la declaración de Francesc Majorot y Vicent Pachet quienes, en efecto, juran que el dicho Cots ha servit de rector e tengut a son càrrech la rectoria dels llochs de Alcodar y Beniopa (...) dient-los misa (...) y administrant-los los sacraments y mostrant la doctrina cristiana y fent lo demés que s'es guarda y toca fer a cascun rector... (73). Al menos se abstienen de hacer constar que lo sabían por experiencia propia...

En esta relación con la iglesia, que podía resultar lo más chocante, y en función de las actividades artesanales desempeñadas por moriscos llegamos a encontrarnos con ornamentos confeccionados por estos infieles. Así, entre el inventario de ropa de la iglesia de San Sebastián de Gandía, hecho en 1535, hallamos, por ejemplo, "...hun vestiment morisch de seda de diverses colors, ab tot son adres a compliment, per a dir missa..." (74).

Son sólo algunos ejemplos, rasgos de una convivencia -decíamos- que, desde luego, no abarcan todos los matices de ésta. Por supuesto, la casuística es mucho más abundante en ejemplos concretos (y estamos plenamente convencidos de que se enriquecerá aún mucho más cuando conozcamos más a fondo el enclave morisco del ducado de Segorbe) y podría argüirse que no rozan el verdadero fondo de la cuestión..., si consideramos que, en efecto, la posición socioeconómica es fundamental. Es decir, ¿el conflicto es sólo, tal y como lo hemos venido planteando hasta aquí, de carácter "cultural", o por el contrario se hace evidente también una discriminación social y económica?; ¿eran los moriscos una minoría económicamente miserable...?

\section{2.- ¿Una discriminación socio-económica...?}

En un artículo reciente, el profesor Ardit se planteaba la hipótesis de si los moriscos valencianos, en el Quinientos, no serían "un grup marginal, numèricament i socialment", pues "el procés de la repoblació, al llarg de la Baixa Edat Mitjana, els havia arraconat, en línies generals, a les pitjors terres"; y, en efecto, acababa confirmando 
que: "Practicaven, amb excepcions importants, una agricultura de subsistència i no poden ser considerats en absolut una força econòmica progressiva. La seua expulsió provocà conseqüències negatives greus, donat que representaven una proporció important de la població, però que en tot cas no foren catastròfiques" (75). Basándose, por una parte, en la evolución de la población a partir del estudio comparativo de los censos al uso (donde se supone que los errores deben hallarse repartidos por igual) $\mathrm{y}$, por otra, en la de la producción agraria según las series de arrendamiento del diezmo -que es de lo que disponemos- desde 1565 hasta 1800 , nada menos, llega a la conclusión de que las zonas valencianas que fueron de moriscos, a partir de 1609 crecen menos en uno y otro sentido que las de población cristiana, de donde se deduce que los moriscos debían cultivar, en general, unas tierras marginales, que luego resultaron, por tanto, poco atractivas para los nuevos repobladores cristianos...

No nos duelen prendas, antes al contrario, reconociendo lo mucho que debemos a este trabajo, extraordinariamente sugerente, aunque nuestras conclusiones al respecto sobre la huerta de Gandía son muy distintas del panorama que aquí se nos dibuja. Para decirlo brevemente, pues no disponemos ahora de más espacio: el siglo XVI (y, sobre todo, su primera mitad, años que van desde la regencia de María Enríquez hasta el gobierno de su nieto, el IV duque santo) es la época de máximo esplendor del ducado en todos los sentidos (los dominios señoriales de los Borja se completan con nuevas adquisiciones, en Gandía se amplían el edificio de la Colegiata -y trabaja aquí el pintor Pablo de San Leocadio- así como el hospital, el propio recinto urbano -es la llamada "Vilanova"- y las murallas, San Francisco funda la Universidad...); pues bien, todas esas realizaciones se hacen posible, en buena medida, gracias a las suculentas rentas que derivan del azúcar (el capítulo más importante, con diferencia, de los ingresos señoriales) y el azúcar está directa e íntimamente ligado aquí a la población morisca como mano de obra experta en el cultivo de la "canyamel" y, sobre todo, en su elaboración (76).

Por lo demás, tampoco parece que aquí los moriscos trabajaran tierras marginales, sino también las más fértiles de huerta como los cristianos viejos. Precisamente la amplia documentación conservada en relación con asuntos de riego (litigios, "tachas" de muy distinta índole, organización o actuaciones en tiempo de sequía, etc...) permiten conocer mucho mejor la distribución de esta tierra -cuestión muy significativa, desde luego- que el caso de los secanos (por más que éstos ocupaban mayor extensión de terreno en términos absolutos). Aparentemente hallamos una distribución del terrazgo muy desigual entre cristianos y moriscos, en detrimento de los últimos. Ya Adelina Bataller se hizo eco de la gran fragmentación de la tierra cultivada por conversos, así como las reducidas dimensiones de sus explotaciones (77). Y, en efecto, nosotros mismos hemos comprobado cómo, en 1593-1601, mientras la extensión media de la tierra de regadío en la cuenca del Vernissa era de unas 12 hanegadas/"hereter" en Gandía "vila", en los demás lugares (moriscos) la posesión media de estas tierras era sensiblemente menor (en torno a las 7 hanegadas/"hereter"). Pero estas cifras resultan engañosas porque cuando hablamos de "extensión media" de tierra en manos de "cristianos viejos", estamos sumando -en este caso concreto, por ejemplo- las $87^{\prime} 5$ hanegadas de 
la Compañía de Jesús ahí o las 69 de Francesc Joan Navarro..., con las de Batiste Alba, Josep Calatayud o Blas de Tejada... quienes solamente poseían 2 hanegadas cada uno de ellos. Es decir, si esos mismos datos los presentamos de manera más pormenorizada, hallamos que el $47^{\prime} 69 \%$ de los regantes cristianos poseían una cantidad de tierra que no llegaba a las 7 hanegadas (lo cual sí coincide con la extensión media de la tierra poseída en esos lugares de moriscos a los que nos referíamos) y el 70'76\% menos de 15 hanegadas; mientras -eso sí- sólo 12 "hereters" cristianos (el 9'23\% de ellos) disponía de $567^{\prime} 5$ hanegadas en total (que era el $35^{\prime} 60 \%$ de de dicha tierra) (78). Es ésta una precaución elemental, pero que no debe olvidarse, a la hora de abordar tal asunto para no incurrir en el vicio más ramplón de las estadísticas basadas en medias aritméticas.

Nuestra impresión, en fin, es que en el seno de las aljamas que nosotros hemos estudiado no existía una diferenciación social tan acusada como en la sociedad de los cristianos viejos, y que, definitivamente, las condiciones de vida (su situación económico-social) del morisco no debían diferir sustancialmente de la de la mayor parte de la población cristiana vieja, en uno ni en otro sentido.

En cuanto a esas diferencias internas, sí hay, desde luego, individuos conversos destacados por su posición social (Francesc Xep, por ejemplo, que era de Benirredrà, es en 1603-1604 el abastecedor de carnes de Gandía y arrendatario, en 1603, de las rentas del señor de Daimuz, aparte de importante poseedor de tierras con más de 50 hanegadas sólo en la huerta regada por el Vernissa); pero es más frecuente aquí hallar personajes relevantes por su ascendiente moral en la comunidad islámica, como los famosos alfaquís Bolaila, Zumilla o Moscayre (con quien el erasmista Bernardo Pérez de Chinchón, que fue profesor en la Universidad de Gandía, consulta -lo confiesa él en el Prólogo- a la hora de redactar su célebre Antialcorán).

En Elche, sin embargo -lo ha demostrado brillantemente J.Serrano Jaén- sí se observa con más claridad que "lentament l'antiga aljama ha anat patint un procés de diferenciació social interna, com es manifesta des de l'últim terç del segle XV als protocols notarials" (79). Por otra parte, de nuevo nos encontramos con una agricultura morisca que está muy lejos de ser meramente de subsistencia ni relegada a las peores tierras; antes al contrario, hallamos que estos conversos ilicitanos van ampliando considerablemente las tierras de labor, sobre todo de cereales (cebada principalmente), barrilla (en función de la producción de jabón) y olivos para aceite (árboles estos que "estan en les millors terres regades"); que disponen de una abundancia de numerario suficiente, por ejemplo, para satisfacer el diezmo o el morabatín en dinero, lo que abona la idea del autor en el sentido de que "...part considerable de les terres conreables eren orientades cap a la producció d'excedents agraris..." con los que se abastecía un mercado comarcal formado, sobre todo, por las morerías de Albatera, Crevillente o el valle de Elda, pero también universidades cristianas... En definitiva, como declara Jeroni Garcia (labrador) en un pleito que tiene lugar en 1615, si hoy estuvieran los moriscos ...se apoderaran de los mejores olivares y tierras de las situadas en el Franco (una partida) porque siempre ivan mercando tierras y olivares en dicha parti$d a$ (cosa que, en efecto, confirman las fuentes disponibles) (80). 
También Pau Ferrer Naranjo se cuestionaba en su tesis (vid. nota 21) la precaria condición económica de los moriscos y, estudiando los de realengo, detectaba un dinamismo semejante por parte de esta población minoritaria, puesto de manifiesto a través de nuevas adquisiciones de tierras tanto en otros realengos como también incluso en zonas de señorío; de manera que -según el comisario regio Adrián Bayarte- el valor de los bienes dejados por los moriscos en lugares de realengo tras 1609 superaría las 230.000 libras valencianas. En cualquier caso, no se hacía necesaria la comprobación empírica de esa dualidad de ámbitos jurisdiccionales en los que un mismo morisco podía poseer tierras, para llegar a la conclusión de que el vasallo enfiteuta (la característica más común entre los moriscos) podía, a su vez, poseer también bienes alodiales pues es claro que la enfiteusis no hace incompatibles otras formas de cesión de esos bienes, así como tampoco implica una determinada situación social (el enfiteuta puede ser un individuo de cualquier condición social y, a la vez, incluso ser arrendador de ese mismo bien que él tiene a censo fijo y un tercero explota como arrendatario).

También en el vecino Aragón, como en Valencia, la mayor parte de los moriscos vivían en zonas de señorío y las conclusiones al respecto de G. Colás apuntan en este mismo sentido: "la minoría se asentaba en las mejores tierras de Aragón donde se aglutinaba la mayor parte de la población aragonesa"; afirma que sus rendimientos agrarios eran superiores y que, en fin, "a pesar de los testimonios en contra es muy posible que el morisco aragonés no fuera tan pobre como afirmaron los contemporáneos" (81). En el otro reino limítrofe con Valencia por el sur, de los 6.562 moriscos murcianos que salieron por Cartagena en abril de 1610 , sólo "se hallaron novecientos pobres [el $137 \%$ ] a quienes fue menester socorrerles para su embarcación del servicio que hicieron a Vuestra Majestad los ricos..." (82).

Es claro, desde luego, que la agricultura era la ocupación principal de la mayoría de los moriscos valencianos (también de los aragoneses y murcianos; no de los abulenses, que eran urbanos). Sin embargo, otras actividades económicas, que suelen ser más difíciles de rastrear, tienen también una importancia que no debe despreciarse y que tampoco debemos entender como desligadas por completo de la labranza. Por una parte, porque en muchos casos constituyen un complemento indispensable en la precaria renta del pequeño campesino; por otra, en sentido muy diferente, porque los beneficios de la tierra sirven para financiar estas otras actividades y viceversa. Lo diremos, mejor, con dos ejemplos concretos de entre otros varios que se podrían aducir: en las capitulaciones matrimoniales que se firman (10-VIII-1601) entre F. Gazel, de Benipeixcar, y Gerónima Piquet, de Beniarjó, el novio aporta tan sólo 6 hanegadas de tierra (muy dispersas, además), pero 205 libras en metálico que se suman a las 250 de la dote de la novia (83); la desproporción entre esa superficie de tierra y la cantidad de dinero es evidente e imposible de explicar con la sóla dedicación a la agricultura. En cambio, el traficante de ganado más importante del arrabal de San Juan, en Elche, a principios del s. XVII es Joan Zom; entre 1600 y 1609 había invertido unas 200 libras en adquirir tierras para ampliar su cabaña, pero también para especular con ellas tras mejorarlas (84).

Precisamente la ganadería es una de esas actividades en la que destacan los moris- 
cos, no sólo como tratantes o dueños, en algún caso, de un número relevante de cabezas de ganado sino también dedicándose a la crianza especializada de animales. En Valldigna la ocupación ganadera adquiere una evidente importancia entre sus habitantes musulmanes, tanto en función del matadero como también para comercializar las reses como animales de labor y explotar otros productos derivados de ellas. Por ejemplo, Jaie Nahem (ni más ni menos que Juan de Borja, tras la conversión forzosa) en 1526 le vende al monasterio de Santa María 91 libras de cera de sus colmenas, pero es dueño, además, de un número elevado de ovejas, cabras, toros y vacas (aparte las posesiones en tierras que tiene en el "magram"); durante estos años nos aparece varias veces como arrendatario del "carnatge", además de recurrir a arrendatarios y medieros para la explotación de su negocio (85). En Gandía, por otro lado, no son extraños contratos como éste por el que el notario Jaume Servés cedía, 24-IX-1602, ...ad medias sive a miges vobis (...) Josepho Tatay, ministro justiciae... villae Gandiae..., noviter converso..., un potro pili gris, pretio et stimatione viginti librarum..., per a que tingau aquell tractant-lo y criant-lo bé, a ús y costum de bon miger..., con la condición de que no trabajara con él y de repartirse al $50 \%$ el precio de venta, deduidas las cantidades que el moriscos haya percibido hasta entonces; el 9 de octubre de 1602 este mismo notario entrega otro potro, bajo idénticas condiciones, a F. Buquet, morisco de Benieto; en 1603 Luis Polit, morisco de Benipeixcar, está criando una "somera" del tintorero Yványez por 12'5 libras y Melchor Padou, también de Benipeixcar, un potro del mercader F. Ferrandis por 43 reales castellanos y precio de venta a medias... (86).

La producción artesanal y el comercio serían otras actividades desempeñadas por moriscos con una relevancia mayor de lo que muchas veces se ha dado a entender (aunque no debemos exagerarlas), pero que tampoco podemos desarrollar aquí y ahora con el detenimiento que la cuestión merece. Ha quedado ya indicada la importancia que el azúcar tiene en Gandía o la seda en Murcia y, en ambos casos, su vinculación directa con los moriscos. En Gandía (e incluimos aquí siempre los lugares de su huerta) nos ha llamado la atención la cantidad de objetos (tejidos y joyas, sobre todo, pero también incluso muebles) que hallamos "fets a la morisca" en distintos inventarios ("post mortem", con motivo de embargos, etc...) (87); de hecho, en el Cappatró del raval de Gandia de les cases y obradors de aquell, que es de 1564, contamos 94 casas y 42 "obradors" (88), denominación en la que se incluyen también las tiendas..., alguna de las cuales, por cierto, conocemos muy bien, como es concretamente la de Gerónimo Hoix (que estaba en la plaza del arrabal) gracias a la transcripción de sus cuadernos de cuentas que nos facilita Ana Labarta (89). Aquí mismo, en fin, por los años de las Germanías, el moro de Benipeixcar Alí Faraig (alias "Malcarat") abastece a la "vila" de "pilotes de pedra per a gombardes" (se le compran por docenas, a 4 sueldos cada docena) y Borexgut, moro de Xàtiva que era carpintero, hace en varias ocasiones "grosses y taps de fusta per a les gombardes..." (90).

Manejando sólo fuentes agrarias, Alí Moferig, moro de Valldigna, sería para nosotros, en fin, un modesto campesino pues no pagaba sino 80 "sous" de "magram"; sin embargo las deudas de las que era acreedor en el momento de su muerte (año 1534) ascendían a casi 25.000 sueldos por distintos negocios con gentes de Xàbia hasta 
Xàtiva y aún otros fuera de Valencia (91). Los ejemplos son mucho más numerosos, hasta el punto de que "més que en cap altre sector econòmic -escribe este mismo autor-, és en el comerç dels draps on es detecta la participació més animada dels membres destacats de la comunitat camperola, tot duent-los com a traginers comercials de poc pes a les comarques veïnes, o com a mercaders de certa entitat a negociar amb aquesta matèria especulativa fora de les fronteres del regne..." (92). Ante todo ello es necesario preguntarse hasta qué punto los casos concretos como éstos, y los muchos más que se tienen documentados, pueden considerarse representativos. Por nuestra parte, no sólo no se nos escapa esta cuestión sino que somos perfectamente conscientes de que nuestra aportación original al tema se ha centrado sobre una zona -la huerta de Gandia-que, en efecto, presenta unas características "a priori" poco comunes: hablamos de unas ubérrimas tierras de regadío, ubicadas en el litoral valenciano y con una intensa población musulmana (lo que ciertamente no es la situación más frecuente en Valencia, como dejara aclarado H. Lapeyre), en las que se cultiva una planta tan rentable, aunque extraña en estas latitudes, como la "canyamel"... y hemos llegado a la conclusión de que "la condición social de los moriscos" (como diría F. Janer) no la entendemos, en cuanto a su nivel económico, sustancialmente diferente a la de la mayor parte de los vasallos cristianos... Es decir, ni estamos ante un "subproletariado rural en estado miserable" (como ha escrito A. Castillo), ni tampoco ratificaríamos la expresión de E. Císcar al hablar de una "clase media kulak-morisca" (93).

Es posible, empero, que estemos equivocados y no tendremos inconveniente alguno en corregir nuestra interpretación, cuando se nos demuestre que es torcida. Pero se nos concederá también que la única manera de salir de estas dudas será comparando este enclave con otros y, a medida que vamos disponiendo de más monografías locales, nuestras conclusiones no parecen tan excepcionales (eso creemos nosotros), como van revelando los casos de Elche o Valldigna y también lo hará, estamos convencidos de ello, el del ducado de Segorbe cuando lo podamos conocer más a fondo... La vida cotidiana de los moriscos, el día a día (que, al cabo, es lo que importa) lo hallamos en los pleitos, fuentes municipales y parroquiales, protocolos notariales, los papeles de la Inquisición (visitas, cuadernos de confesores, procesos, también las relaciones de causas de fe)... y es mucho todavía el camino que queda por recorrer en este sentido. Pero cuando se profundiza en esa documentación, como hace, por ejemplo, R. Carrasco al estudiar los procesos del Santo Oficio, no es extraño llegar a la conclusión de que "se debe revisar la vieja idea según la cual los moriscos valencianos eran en su inmensa mayoría campesinos sumisos y muertos de hambre. Sin caer no obstante en la exageración inversa" (94). Y en eso estamos.

\section{NOTAS}

(1).- Cfr.: Míkel de EPALZA, Mª J.PATERNINA y A. COUTO: Moros y moriscos en el Levante Peninsular (Sharq Al-Andalus). Introducción bibliográfica, Instituto de Estudios 
Alicantinos, Alicante, 1983 (que sería conveniente actualizar hasta la fecha) y los estudios de: R.CARANDE: "Los moriscos de Henri Lapeyre, los de Julio Caro y algún morisco más", Moneda y crédito. Revista de economía, $\mathrm{n}^{\mathrm{o}} 78$ (Madrid, 1961), 9-26 (recogido en Otros siete estudios de historia de España, Ariel, Madrid, 1978, pp.: 317-349); R. GARCIA-CARCEL: "La historiografía sobre los moriscos españoles. Aproximación a un estado de la cuestión", Estudis-6 (Univ. de Valencia, 1977), 71-99; M.A. DE BUNES IBARRA: Los moriscos en el pensamiento histórico (Historiografía de un grupo marginado), Cátedra, Madrid, 1983; M. GARCIA-ARENAL: "Ultimos estudios sobre moriscos: estado de la cuestión", Al-Qantara (Revista de Estudios Arabes), IV, fasc.: 1 y 2 (1983), 101-114, que completa al anterior comentando la producción bibliográfica desde 1980. Sobre los mudéjares, M. RUZAFA GARCIA: "Los mudéjares valencianos en el siglo XV. Una perspectiva bibliográfica", Actas del III Simposio Internacional de Mudejarismo, Teruel, 1986, 291-303. (Para la reseña bibliográfica de los autores y obras que citamos en nuestro texto - al menos las más conocidas- remitimos a estos estudios).

(2).- Una y otra, empero, comparten semejante suerte desgraciada en cuanto a su difusión: la de mosén Boronat, hace tiempo agotada e imposible de encontrar, sin embargo no ha sido reeditada pese al enorme interés de su apéndice documental (aparte el historiográfico); en cuanto a The moriscos of Spain: their conversion and expulsion tampoco es fácil de comprender el que hasta ahora no se hubiera traducido y, al fin, está próxima a aparecer la versión en castellano por obra del Instituto "Juan Gil Albert" de la Diputación de Alicante.

(3).- Entre el 4 de febrero y 29 de marzo de 1889, M. DANVILA pronunció unas conferencias en el Ateneo de Madrid que fueron recogidas en La expulsión de los moriscos españoles, Madrid,1889; R.CHABAS: "Los moriscos de Valencia y su expulsión", El Archivo, IV (1898), 231-234 y 373-388.

(4).- Historia de los heterodoxos españoles, Lib. IV ("Protestantismo y sectas místicas"), CSIC, Valencia, 1964, $2^{\text {a }}$ ed. (preparada por Enrique Sánchez Reyes), pp.: 339 y 343. Como es sabido, según Boronat la expulsión se demora durante tanto tiempo por el apoyo interesado de la nobleza a estos vasallos apóstatas, anteponiendo egoístamente sus intereses materiales a los más sublimes de la unidad religiosa. Es éste uno de los argumentos que reitera a lo largo de su obra, así como la defensa de la figura histórica del Patriarca Juan de Ribera, quien acaba convirtiéndose en uno de los más firmes adalides de la expulsión (Cfr., de este mismo autor, El B. Juan de Ribera y el R. Colegio de Corpus Christi, Imprenta de F. Vives y Mora, Valencia, 1904).

(5).- Disponemos de ediciones recientes de: F.JANER: Condición social de los moriscos de España: causas de su expulsión y consecuencias que ésta produjo en el orden económico, Real Academia de la Historia, Madrid, 1857 (ed. facsímil por la editorial Alta Fulla, Barcelona, 1987); J. MUÑOZ Y GAVIRIA: Historia del alzamiento de los moriscos, su espulsión de España y sus consecuencias en todas las provincias del Reino, Madrid, 1861 (ed. facsímil por Librerías París-Valencia, Valencia, 1980). Igualmente de la Historia del País Valenciano de V. Boix y Ricarte (Valencia, 1845, 2 vols.), que incluimos aquí pese a su carácter no monográfico, por el tratamiento que da a la cuestión morisca, se ha hecho una reedición, con introducción de P. Ruiz Torres, en Eds. Cupsa y Planeta, Barcelona, 1980.

(6).- De hecho, sobre la época mudéjar inmediata al bautismo forzoso, durante mucho tiempo prácticamente no hemos dispuesto sino de los estudios de: Leopoldo PILES ROS: $L a$ situación social de los moros de realengo en la Valencia del siglo XV, Madrid, 1949; M.GUAL CAMARENA: "Mudéjares valencianos. Aportaciones para su estudio", Saitabi-IX, n 33-34 (1949), 165-199 y Francisco A. ROCA-TRAVER: "Un siglo de vida mudéjar en la Valencia medieval (1238-1338)", Estudios de Edad Media de la Corona de Aragón-V (Zaragoza, 1952), 115-208. 
(7).- Cfr. bibliografía de estos autores que se recoge en obras citadas en nota 1, a la que cabría añadir otros estudios más recientes (aparecidos después de 1983) como, por ejemplo: de M. de EPALZA: "El català al Màgreb àrab. Els moriscos expulsats", Segon Congrés Internacional de la Llengua Catalana, VIII (Valencia, 1989), 385-388; junto con F.Ll. Bernabé: "Els moriscos valencians a l'exili després de l'expulsió del 1609", Afers-7 (Catarroja, 1989), 207-214. De M" C. BARCELO: Minorias islámicas en el País Valenciano. Historia y dialecto, Univ. de Valencia e Insto. Hispano-Arabe de Cultura, Valencia, 1984. De A. LABA RTA: La onomástica de los moriscos valencianos, CSIC, Madrid, 1987. Es de lamentar, a este propósito, la ausencia de una cátedra de árabe en la Universidad de Valencia.

(8).- Moriscos y cristianos. Un enfrentamiento polémico (1492-1640), FCE, Madrid, 1979 (ed. original de 1977), en donde se hace uso de manuscritos aljamiados. Desde este punto de vista, podríamos considerarlo como una especie de continuación de la obra clásica del P. Pedro LONGAS: Vida religiosa de los moriscos, Imprenta Ibérica, Madrid, 1915 (hay ed. facsímil por la Universidad de Granada, 1990, con estudio preliminar a cargo de Darío Cabanelas O.F.M.).

(9).- François DOSSE: La historia en migajas (De "Annales" a la "nueva historia"), Edicions Alfons El Magnànim. IVEI, Valencia, 1988.

(10).- Buena muestra de ello pueden ser estas dos recopilaciones de artículos dispersos suyos, a cargo ambas de la Diputación Provincial de Granada: Andalucía en la Edad Moderna: Economía y Sociedad, 1985 y Minorías y marginados en la España del siglo XVI, 1987, aparte de su conocida obra de síntesis, junto con A.Domínguez Ortiz: Historia de los moriscos. Vida y tragedia de una minoría, Revista de Occidente, Madrid, 1979 (1ª ed. de 1978).

(11).- Cfr.: M. GARCIA-ARENAL: Inquisición y moriscos. Los procesos del tribunal de Cuenca, Siglo XXI, Madrid, 1978; Jean VIDAL: Quand on brûlait les morisques (1544-1621), Nîmes, 1986; Rafael CARRASCO: "Historia de una represión. Los moriscos y la Inquisición en Valencia 1566-1620", Areas (Revista de Ciencias Sociales)-9 (Murcia, 1988), 25-50; M" C. BARCELO TORRES: "La Inquisició i els moriscos", Debats-2/3 (1982), 18-24. Aparte de estos estudios específicos, naturalmente son numerosas las referencias a los moriscos y el Santo Oficio en las obras renovadoras sobre la Inquisición de J. Contreras, J.P. Dedieu, B. Bennassar, R. García-Cárcel, R.Carrasco, J.Blázquez Miguel...

(12).- Sobre esta cuestión nos hemos ocupado con más detalle en S. LA PARRA: "Metodología y fuentes locales en Valencia: Consideraciones sobre su aplicación a la historia del siglo XVII", comunicación presentada a las Jornadas sobre Fuentes y Métodos de la Historia Local (Zamora, octubre de 1990), en prensa.

\section{(13).- M. GARCIA-ARENAL: "Ultimos estudios...", 113.}

(14).- Cfr.: Alain CROIX et Didier GUYVARCH (sous la direction de): Guide de l' Histoire Local. Faisons notre Histoire!, Éditions du Seuil, Paris, 1990, en donde se tratan las posiblidades que ofrece esta "nueva" tendencia, desde la explotación de protocolos notariales hasta la "historia oral".

(15).- En el ducado de Gandía, por ejemplo, hemos encontrado una fuente físcal -el ducat de foc- exclusiva de los moriscos y que nunca antes habíamos visto utilizada. Su interés demográfico es evidente, habida cuenta de que nos proporciona una relación anual de las casas habitadas y deshabitadas (las cuales pagaban sólo medio ducado y su número cambia de un año para otro), Cfr.: Santiago LA PARRA: "Fiscalidad morisca en el Ducado de Gandía: el ducat de foc", V Simposio Internacional de Mudejarismo (Teruel, septiembre 1990), en prensa.

(16).- Cfr.: F. CHACON JIMENEZ: "La familia en España: una historia por hacer", $L a$ familia en la España mediterránea (siglos XV-XIX), Centre d'Estudis d'Història Moderna 
"Pierre Vilar"-Ed. Crítica, Barcelona, 1987, 13-35, recogido también en: F. CHACON (ed).: Historia social de la familia en España. Aproximación a los problemas de familia, tierra y sociedad en Castilla (ss .XV-XIX), Instituto de Cultura "Juan Gil Albert", Alicante, 1990, 13-30.

(17).- Es muy probable que cuando estas líneas sean publicadas haya aparecido ya la edición de su tesis doctoral; mientras tanto, y como anticipo del buen hacer de este historiador, contamos con varios trabajos suyos -a partir de los cuales se hace necesario matizar la vieja visión de los moriscos castellanos como una pobre minoría dedicada a la venta ambulante- como: "La opresión fiscal de la minoría morisca en las ciudades castellanas. El caso de la ciudad de Avila", Studia Historica ( $H^{a}$ Moderna), IV, 3 (Univ. de Salamanca, 1986), 17-49; "Personalidad étnica y trabajo artístico. Los mudéjares abulenses y su relación con las actividades de la construcción en el siglo XV", Medievalismo y Neomedievalismo en la arquitectura española. Aspectos generales (ed. de: P. Navascués Palacio y J.L. Gutiérrez Robledo), Univ. de Salamanca, 1987, 245-252; "Nivel de alfabetización en una ciudad castellana del siglo XVI: sectores sociales y grupos étnicos en Avila", Studia Historica..., VI (1988), 481-502 o "Los mudéjares de la extremadura castellano-leonesa: notas sobre una minoría dócil (1085-1502)", Ibidem, VII (1989), 95-125.

(18).- Cfr.: "Alguns aspectes de la repoblació de Miravet (Ribera d'Ebre) després de l'expulsió dels moriscos (1610-1623)", Pedralbes (Revista d'Història Moderna)-6 (Barcelona, 1986), 39-70; La Orden de San Juan de Jerusalén y Miravet. Dominio señorial y cambios institucionales (Primera mitad del s.XVII), Institut d'Estudis Tarraconenses "Ramón Berenguer IV", Tarragona, 1988; Els hospitalers a la Ribera d'Ebre. Benissanet, ss. XVI-XVII, Diputación Provincial, Tarragona, 1990; "La fiscalidad mudéjar en Cataluña", ponencia al $V$ Simposio Internacional de Mudejarismo (Teruel, septiembre 1990) en prensa o "Los sarracenos del Ebro catalán (ss. XII-XV): una aproximación", ponencia al Congrs. Intern. "380 Aniversari de l'Expulsió dels Moriscos. Port dels Alfacs (Sant Carles de la Ràpita, diciembre 1990), en prensa.

(19).- Las líneas desarrolladas aquí (Fundació "Milà i Fontanals") han sido, entre 1982 y 1984: "Relaciones entre cristianos y mudéjares en los estados de la Corona catalano-aragonesa en el siglo XIV" y, más tarde (1986-1989): "La frontera terrestre y marítima con el Islam". De algunos de los estudios surgidos de este seminario nos hacemos eco, más abajo, en las páginas de este trabajo.

(20).- Cfr.: G. COLAS LATORRE: "Los moriscos aragoneses y su expulsión", Destierros aragoneses. I: Judios y Moriscos, Institución "Fernando El Católico", Zaragoza, 1988, 189-215, en donde lamenta el autor ese paupérrimo estado de la cuestión. Aquí, en cambio (a diferencia de lo que ocurre en Valencia y con el antecedente ya clásico del estudio en los años 20 de F. Macho Ortega sobre la condición social de los mudéjares aragoneses) sí se ha hecho más hincapié en la época mudéjar, como lo prueba la investigación de $M^{a}$ Luisa Ledesma Rubio (de la escuela de D. José M $\mathrm{M}^{\mathrm{a}}$ Lacarra) y los cinco Simposios Internacionales que ya se llevan celebrados en Teruel sobre mudejarismo, a cuyas actas nos remitimos.

(21).- El último de estos trabajos, que nosotros conozcamos, es la espléndida tesis doctoral (leída en la Univ. de Valencia a finales de 1990), de Joaquín SERRANO JAEN: Estructures agraries al sud del País Valencià. Propietat, règim d'explotació $i$ distribució social de la terra a Elx: de la problemàtica morisca a la consolidació de la revolució burgesa (1600-1855), 4 vols. Casi diez años antes se había leído otra tesis en la Univ. de Barcelona, sobre los moriscos valencianos de realengo, que ya aportaba algunas novedades muy interesantes: Pablo FERRER NARANJO: Los moriscos de la Corona de Aragón. La propiedad morisca en los realengos de Valencia en 1609, 1981, 3 vols. Entre una y otra, y sin ánimo de exhaustividad, podemos destacar también los trabajos de: Juan Bta. VILAR: "Moriscos granadinos en el sur valenciano", Estudis-9 (1981-82), 15-47. Mario MARTINEZ GOMIS: "El control de los niños moriscos en 
Alicante tras el decreto de expulsión de 1609", Anales de la Universidad de Alicante. $H^{a}$ Moderna-1 (1981), 251-280. Primitivo J.PLA ALBEROLA: “Acerca de los contratos agrarios de los mudéjares valencianos: los "capítols" de Catamarruc", Anales de la Universidad de Alicante. $H^{a}$ Medieval-2 (1983), 119-138; "Exáricos valencianos", España y el Norte de Africa. Bases históricas de una relación fundamental... (1984), 391-398. Josep TORRO I ABAD: "Església i Moriscos a la Vall de Gallinera (1578-1583). Aspectes Econòmics de l'Enfrontament", I Congrés d'Estudis de la Marina Alta (1986), 291-301. Vicente CIMENEZ CHORNET y J.PASTOR FLUIXA: "Demografia, producció delmal i productivitat a Xaló, Vall d'Alcalà i Pedreguer (1555-1800)", Aguaits-1 (1988), 5-17. Francisco PONS FUSTER: Aspectos económico-sociales del Condado de Oliva (1500-1750), Publicaciones del Ayuntamiento de Oliva, Valencia, 1981. Antonio MESTRE: "Un documento desconocido del Patriarca Ribera escrito en los momentos decisivos sobre la expulsión de los moriscos", Estudios dedicados a Juan Peset Aleixandre (Univ. de Valencia, 1982) II, 733-739. Uno de los trabajos más innovadores e interesantes es, en nuestra opinión el de Ferran GARClA-OLIVER: El monestir i la mesquita. Societat i economia agrària a la Valldigna (segles XIII-XVI), tesis de doctorado inédita, Univ. Valencia, 1986, 2 vols. Adela MORA CAÑADA: Monjes y campesinos (El señorio de la Valldigna en la Edad Moderna), I.E “Juan Gil Albert"-CEIC “Alfons El Vell”, Alicante, 1986. Encarnación GIL SAURA: "La expulsión de los moriscos en Alzira. Aspectos económicos (1609-1616)", Estudis-9 (1981-82), 49-80. Tomás PERIS ALBENTOSA: Propiedad y dinámica social en un realengo valenciano (Alzira, 1465-1768), tesis doctoral leída en la Univ. de Valencia, 1988, 5 vols. (de la que se ha publicado una parte, pero no se incluyen precisamente los capítulos referidos a los moriscos). Rafael BENITEZ SANCHEZ- BLANCO: "Las cartas pueblas del Condado de Carlet y los conflictos sobre su aplicación", Saitabi-XXXVI (1986), 187-212; "Un plan para la aculturación de los Moriscos valencianos: 'Les ordinacions' de Ramírez de Haro (1540)", Les morisques et leur temps, ECNRS, Paris, 1983, pp.: 125-157 . Vicent VALLES I BORRAS: "Germania i Senyoriu: La Baronia de Carlet", Al-Gezira-3 (1987), 133-157. Ricardo FRANCH: "Les conseqüències de l'expulsió dels moriscos a Corbera", I Assemblea d' Història de la Ribera: Economia Agrària i Local (1981), 347-362. Eugenio CISCAR: "Notas sobre la predicación e instrucción religiosa de los moriscos en Valencia a principios del siglo XVII", Estudis-15 (1989), 205-244, en donde además de un enfoque general de la cuestión, se hace hincapié en el caso de la diócesis de Orihuela y, sobre todo en "la agresiva actuación pastoral de D. Feliciano de Figueroa en la diócesis de Segorbe" (el autor, nos anuncia aquí un estudio en curso sobre "la élite" morisca que esperamos con verdadero interés). Lamentablemente el ducado de Segorbe (el señorío con más número de moriscos en todo el antiguo reino de Valencia) no ha sido investigado monográficamente todavía -al menos que nosotros sepamos- aunque esperamos que lo haga pronto Magín ARROYAS SERRANO, quien nos ha avanzado algunos artículos con referencias muy interesantes a esta zona, como "El viratge filipí' en la política sobre els moriscos valencians, 1554-1564", Afers 5/6 (Catarroja, 1988), 193210 y, en colaboración con Vicent GIL VICENT: "Revuelta y expulsión: los procesos inquisitoriales de los dirigentes moriscos de la sierra de Espadán en 1568", comunicación presentada al Congr. Intern. sobre el 380 Aniversari... (Sant Carles de la Ràpita, 1990), en prensa. Nosotros mismos, en fin, nos hemos ocupado de la situación en otra zona (la huerta de Gandía) particularmente relevante también en este aspecto y que, sin embargo, tampoco estaba estudiada: El ducado de Gandía en el siglo XVII: la ruptura de una convivencia tras 1609, tesis doctoral, Univ. de Valencia, 1990, 2 vols., aparte de otros trabajos menores, actualmente en prensa, sobre la fiscalidad morisca o la repoblación del ducado tras 1609.

(22).- J. CARO: Los Moriscos..., 51. 
(23).- A.DOMINGUEZ ORTIZ y B.VINCENT: Historia de los moriscos..., 43 (subrayados nuestros).

(24).- CSIC (Anuario de Estudios Medievales. Anex 16), Barcelona, 1987, en donde, por cierto, la autora rechaza el uso del término "mudéjar" por considerarlo ajeno a la tradición historiográfica catalana, en aras de los más comunes de "sarrahí" o "moro", en los que, además, aprecia "la virtut de recordar-nos permanentement que, ab ulls del poble cristià comú, uns i altres (peninsulares y los de Berberia) eren en el fons el mateix: infidels i enemics, i aquests sentiments eren els que s'imposaven en moments de crisi" (p.: XV).

(25).- Ibidem, p.: XIII (subrayados nuestros). Sobre la segregación matiza, a continuación, que "...no eren els cristians els únics que la volien; també la exigien les lleis sarraïnes, ja que la minoria musulmana volia, igualment, salvaguardar la seva pròpia identidat religiosa"; también, que no sólo los moros eran sujeto paciente de discriminación: las restricciones a la libertad de movimientos, por ejemplo, las sufrían asimismo, los "pagesos de remença" por ejemplo, y aún añade que "els mals usos, que gravaven els camperols d'aquesta condició, eren tan durs o més que els impostos i serveis que afectaven els sarraïns".

(26).- Una espléndida síntesis de esta polémica en: H.LAPEYRE: "Deux interprétations de l'histoire de Espagne: Américo Castro et Claudio Sánchez Albornoz", Annales. Economies. Societés. Civilisations (1965), 1.015-1.037.

(27).- "El tono de vida en la Valencia medieval. El ritmo del tiempo", BSCC, primera parte en LVIII, cuaderno II (1982), 239-308 y la continuación en: LIX, cuaderno I (1983), 1-81; cit. de p.: 273 .

(28).- Cfr.: K. W.BUTZER, J.F.MATEU, E.BUTZER y P.KRAUS: “L'origen dels sistemes de regadiu al País Valencià: romà o musulmà?, Afers-7 (1988-89), 9-68.

(29).- París, 1969; traducida al castellano con un título menos provocativo: La revolución islámica de Occidente Barcelona, 1974. Pierre GUICHARD replicaría a esta obra en: "Los árabes sí que invadieron España. Las estructuras sociales de la España musulmana", Estudios sobre historia medieval, IVEI, Valencia, 1987, 27-71.

(30).- "La Valencia musulmana. Introducción", tomo III de Nuestra Historia, Mas Ivars ed., Valencia, 1980, p.: 204 y 205, respectivamente. Del mismo autor: "L'època musulmana, factor de continuïtat o discontinuïtat en la història valenciana", Debats-1 (1982), 8-16. Entre otros muchos autores que avalan esta teoría, Cfr.: Dolors BRAMON: Contra moros $i$ jueus. (Formació i estratègia d'unes discriminacions al País Valencià), Eliseo Climent ed., Valencia, 1981, especialmente pp.: 70 y ss.

(31).- F.ROCA-TRAVER: "Un siglo de vida mudéjar..., que viene a ser una respuesta a los tres volúmenes de la Histoire des mores, mudejares et des morisques ou des arabes d'Espagne sous la domination des chretiens (Paris, 1846) de Albert CIRCOUT. "El tono de vida de la Valencia..." del siglo XV es igualmente optimista a los ojos de este autor (muy diferente al panorama -más realista- que nos presentará E. Belenguer) impregnado -según él- de un "sentido liberal y democrático, consustancial con el temperamento valenciano" (p.: 33), e insiste en que nos hallamos ante una "sociedad verdaderamente democrática" (p.: 260) resultado, en gran parte, de las bases jurídicas fundadas por Jaime 1 ...

(32).- El P. Burns, sin embargo, rechaza de plano esta acusación y esgrime como defensa su intensa dedicación al estudio precisamente del s.XIII valenciano. Cfr.: Moros, cristians i jueus en el regne croat de València (Societats en simbiosi), Eliseo Climent ed., Valencia, 1987 (ed. original, Cambridge U.P., 1984), especialmente p.: 50. Lo último aparecido aquí al respecto es la sección "Debat" del n 1 de la Revista d'Història Medieval (Departament d'Història Medieval de 
la Universitat de València, 1990): “A propòsit de l'obra de R.I. Burns", pp.: 217-247, con colaboraciones del propio P. Guichard, V.M. Rosselló y A. Ferrando.

(33).- P.GUICHARD: "La repoblación y la condición de los musulmanes", Nuestra Historia, III, 43-82 (cit. de p.: 68).

(34).- E. GUINOT RODRIGUEZ: Feudalismo en expansión en el norte valenciano. Antecedentes y desarrollo del señorío de la Orden de Montesa. Siglos XIII y XIV, Diputación de Castellón, Castellón, 1986.

(35).- "Los mudéjares aragoneses: de la convivencia a la ruptura", Destierros aragoneses..., I, 171-188, en donde la autora defiende una postura "continuista" y escribe: "La presencia de las comunidades mudéjares tanto en las ciudades como en el ámbito rural (...) comportaba la coexistencia de dos mentalidades distintas, dos modos de vida que convivirían durante más de cuatro siglos en el solar aragonés" (172). Entiende que mientras la actividad prestamista de los judíos les granjeó a éstos la antipatía popular, la laboriosidad de los moriscos y su dedicación a la tierra o a la artesanía, como mano de obra especializada, les evitó esa situación, hasta el punto de que "en general, en los pueblos de población mixta no existía discriminación en barrios entre una y otra población y la vida cotidiana transcurría sin alteraciones notables" (185).

(36).- M" Blanca BASAÑEZ VILLALUENGA: La aljama sarracena de Huesca en el siglo XIV, CSIC-Institución Milà i Fontanals (Anejo 21 del Anuario de Estudios Medievales), Barcelona, 1989.

(37).- M ${ }^{\mathrm{a}}$.T. FERRER. Els sarraïns de la Corona..., 7.

(38).- B.BASAÑEZ: La aljama sarracena de Huesca..., 71.

(39).- Farhat DACHRAOUI: "Intégration ou exclousion des minorités religieuses: la conception islamique traditionelle", actas del 380 Aniversari de l'Expulsio..., en prensa.

(40).- Cfr.: M. de EPALZA: "Caracterización del exilio musulmán: la voz de mudéjares y moriscos", Destierros aragoneses...I, 217-227, especialmente p.: 222. Bernard VINCENT destaca "dos niveles esenciales de solidaridad: el nivel familiar y el de la comunidad morisca considerada como un conjunto coherente" ("Los elementos de solidaridad en el seno de la minoría morisca (siglo XVI)", Andalucía en la Edad Moderna..., 203-214, cit. de p.: 205) y, en efecto, parece claro (lo ratifican Cardaillac, J.Vidal, García-Arenal...) que dentro de esa familia morisca resulta especialmente destacado el papel de la mujer a la hora de mantener vivas las tradiciones musulmanas (empezando por la lengua árabe, hasta el punto que no es raro encontrar mujeres, ya entrado el siglo XVII, que no hablaban el romance, como hemos podido comprobar nosotros mismos en la Alquería de Tamarit, un pequeño lugar de la huerta de Gandía).

(41).- Louis CARDAILLAC: Moriscos y cristianos. Un enfrentamiento polémico (14921640), FCE, Madrid, 1979, p.: 50.

(42).- Carmen BARCELO TORRES: "La Inquisició i els moriscos", Debats 2/3 (Valencia, 1982), 18-24 (cit. de p.: 20).

(43).- "La diferencia entre las dos comunidades no se basa en el aspecto físico", concluye B. VINCENT en su estudio sobre "¿Cuál era el aspecto físico de los moriscos?”, II Coloquio de Historia de Andalucía (Córdoba, 1983), 335-340 y recogido en Andalucía en la Edad Moderna..., 303-313 (de donde tomamos la cita, en p.: 313).

(44).- Archivo del Reino de Valencia (ARV): Procesos Criminales, caja 1, A-80 (Debo la noticia de este proceso, interesantísimo en sus detalles, a la extraordinaria amabilidad de Vicente Graullera Sanz).

(45).- Un enfrentamiento polémico..., 277. 
(46).- De un Memorial al rey, cit. por BORONAT: Los moriscos españoles..., II, 444-449.

(47).- De otro memorial a Felipe II (octubre de 1566), cit. en: R. GARCIA-CARCEL: Herejia y sociedad en el siglo XVI. La Inquisición en Valencia 1530-1609, Península, Barcelona, 1980, 79 (la misma cita también en p.: 236).

(48).- L. CARDAILLAC: Prólogo a Jean VIDAL: Quand on brûlait..., 6.

(49).- J. BLAZQUEZ MIGUEL: El Tribunal de la Inquisición en Murcia, Academia Alfonso X El Sabio, Murcia, 1986, 121.

(50).- Bernard VINCENT. "Los elementos de...", 206.

(51).- Recientemente Francisco REQUENA AMORAGA ha estudiado el sistema defensivo costero frente al peligro "del mar" y sus conclusiones son poco optimistas acerca de su eficacia. Las razones serían varias: se sigue una estrategia puramente defensiva (basada en fortificaciones costeras y dar los "avisos de moros" cuando se divisara una flota enemiga), la secular penuria económica para el mantenimiento de la infraestructura necesaria (no siempre, además, bien planificada, como ya denunciara a finales del Quinientos el Virrey Don Vespasiano Gonzaga, quien era experto en fortificaciones), la desorganización e ineficacia militar (la Milicia Efectiva defrauda las expectativas puestas en ella cuando se crea) y la poca efectividad del sistema de comunicación entre las torres vigías que jalonaban todo el litoral. Resultado de todo ello sería el que "en ocasiones los guardas se veían obligados a contemporizar con los moros norteafricanos" y que la misma Peñíscola no fuera sino "un presidio mal guardado" (p.: 748); que la torre de Benidorm nunca se llegara a construir (pese a las reiteradas peticiones en este sentido desde Villajoyosa); que el puerto de Moraira -refugio habitual de corsarios- permaneciera sin vigilancia... (La defensa de las costas valencianas en la época de los Austrias. Una contribución al estudio de la historia del Mediterráneom durante los siglos XVI y XVII, Tesis de Licenciatura, inédita, Universidad de Alicante, 1990).

(52).- Cfr.: Santiago LA PARRA: El ducado de Gandía..., I, 330-514.

(53).- En: La Inquisición española. Nueva visión, nuevos horizontes (ed. de J. PEREZ VILLANUEVA), Madrid, 1980, p.: 370 . El propio autor advierte que estas cifras son un cálculo mínimo, estimando en un 25\% el error posible por defecto (Cfr.: Jaime CONTRERAS: El Santo Oficio de la Inquisición en Galicia (1560-1700). Poder, sociedad y cultura, Akal, Madrid, 1982, pp.: 445-458, especialmente la 455 en donde se recogen estas cifras en un cuadro resumen).

(54).- B. VINCENT: "La Inquisición y los moriscos granadinos", en Minorías y marginados..., 119-155.

(55).- R. GARCIA-CARCEL: Origenes de la Inquisición española. El Tribunal de Valencia. 1478-1530, Península, Barcelona, 1976, p.: 167 y Herejía y sociedad en el siglo XVI. La Inquisición en Valencia 1530-1609, Península, Barcelona, 1980, 206 y 208. Según Rafael CARRASCO, "antes de 1566 se debió de procesar a un número de moriscos comprendido entre 200 y 250 , grupo integrado en un $50 \%$ por tagarinos o moriscos aragoneses", de donde se deduce que sí fue respetada la tregua de 40 años convenida en la concordia de 1526 ("Historia de una represión..., 29).

(56).- Ibidem, 31 .

(57).- Cit. por BORONAT: Los moriscos..., I, 135-136.

(58).- Archivo de la Catedral de Valencia, 6.032:3: Copia de una carta de los señores del Consejo de la Sancta General Inquisición para el Santo Officio de la Inquisición de Valencia. Su fecha: en Madrid, 5 de junio 1591 (copia certificada por el notario Nicolás del Río menor). La carta en cuestión era la respuesta de la Suprema a una sugerencia de Valencia, en el sentido 
de actuar con benevolencia para con los moriscos de Gandía que estaban presos y que esto sirviera de ejemplo a los demás para moverles la conversión, e incluía la advertencia (por si nos quedara alguna duda) de que "...en lo general se guarde lo çerca de esto proveydo por el Consejo. Y, ofreçiéndose algún caso particular, veréis, señores, el proçeso con ordinario y consultores y, sin executar lo que acordáredes, lo remitiréis al Consejo para que se probea lo que convenga..." (subrayado nuestro).

(59).- H.KAMEN: La Inquisición española, Alianza, Madrid, 1983 , 384-385 (Cfr.: cap. XIII: "La Inquisición y la política"). Hay una ed. nueva, reelaborada por el autor, en Crítica, Barcelona, 1985, aunque en este punto no cambia nada.

(60).- Antonio de BRUNEL: "Viaje de España", en Viajes de extranjeros por España y Portugal (ed. de J. GARCIA MERCADAL), II: Siglo XVII, Aguilar, Madrid, 1959, 401-521 (cit. de p.: 420). El manuscrito está escrito en 1664 y aparece dos años después.

(61).- G. DUFOUR: La Inquisición española. Una aproximación a la España intolerante, Montesinos, Barcelona, 1986, 58; B.BENNASSAR: "El poder inquisitorial", en Inquisición española: poder político y control social (coordinado por idem), Crítica, Barcelona, 1981, 6893.

(62).- Cfr.: BORONAT: Los moriscos..., I, 197; GARCIA CARCEL: "El itinerario de los moriscos hasta su expulsión (1609)", Inquisición española y mentalidad inquisitorial (ed. de Angel Alcalá), Ariel, Barcelona, 1984, 67-78 y M. GARCIA ARENAL: Inquisición y moris$\cos \ldots, 117$.

(63).- Cfr. a este respecto, aparte las numerosas referencias a la cuestión en obras generales como la de Boronat, L. Cardaillac o los estudios citados de R. García-Cárcel sobre la Inquisición en Valencia y otros, supra en nota 21: Agustín REDONDO: Antonio de Guevara (1480-1545) et l'Espagne de son temps, Ginebra, 1976; R. BENITEZ SANCHEZ-BLANCO y E. CISCAR: "La Iglesia ante la conversión y expulsión de los moriscos", Historia de la Iglesia en España (dirig. por.: R. García-Villoslada), IV: La Iglesia en España de los siglos XVII y XVIII (coord. por A. Mestre), BAC, Madrid, 1979, 253-307; V. CARCEL ORTI: Historia de la Iglesia en Valencia, Arzobispado de Valencia, Valencia, 1984, I, 149-263; A. SALVA Y BALLESTER: "Los moriscos valencianos en 1527 y 1528", BSCC, XVI (1935), 365-376; E. VIDAL BELTRAN: "El Cuaderno de un visitador de moriscos", Estudis-8 (1979-80), 35-69; R. GARCIA CARCEL: "Estudio crítico del catecismo de Ribera-Ayala", Les Morisques et leur temps, ECNRS, Paris, 1983, 159-168. Sobre la erección de las nuevas parroquias: J.SANCHIS SIVERA: Nomenclátor geográfico-eclesiástico de los pueblos de la diócesis de Valencia, Valencia, 1922; R. ROBRES LLUCH: "Catálogo y nuevas notas sobre las rectorías que fueron de moris$\cos$ en el arzobispado de Valencia y su repoblación (1527-1633)", Anthologica Annua, 10 (1962), 143-191 y "Predicadores de moriscos en el pontificado de San Juan de Ribera (15691609)", Corrientes espirituales en la Valencia del siglo XVI (1550-1600), Valencia, 1983, 301309.

(64).- Cfr.: la actitud, por ejemplo, del obispo Esteve en Segorbe, tan radical que hasta chocaba al mismísimo Ribera, personaje no muy sospechoso precisamente de favorecer a los moriscos, en: CISCAR: "Notas sobre la predicación...".

(65).- M. ARROYAS: “El 'viratge filipí'..., 203.

(66).- Cfr.: S. LA PARRA: El ducado de Gandia..., I, 477-486.

(67).- Archivo Histórico Nacional (AHN). Inquisición, leg.: 806 (II): Visita echa en la villa de Gandía, con todos los lugares comarcanos, Valle de Alfande y varonía de Veniarjó y Palma, por el inquisidor Jiménez de Reinoso en el año 1580. 
(68)-- F. CHACON: "El problema de la convivencia. Granadinos, mudéjares y cristianos viejos en el Reino de Murcia. 1609-1614", Mélanges de la "Casa de Velázquez", XVIII-1 (1982), 103-133 (cit. de p.: 105). Las repercusiones en este sentido de la revuelta en Castilla son comentadas también por Domínguez Ortiz y Bernard Vincent (Historia de los moriscos..., 57) y coincide igualmente con el auge de la represión inquisitorial en Valencia, como hemos visto.

(69).- Juan Bta. VILAR: "Moriscos granadinos en el sur valenciano", Estudis-9 (1981-82), 15-47, a donde corresponden las citas que damos aquí. Del mismo autor: "Los moriscos de la gobernación y obispado de Orihuela", Al-Andalus, XLIII, fasc. 1² (1978), 323-367.

(70).- El monestir i la mesquita..., II, 635.

(71).- Para 1487: Roderic FERRER I FORTUNY: "La paraula i la festa litúrgica a Gandia (Métodes Municipals de cristianització al segle XV)", Ullal-5 (Gandia, 1984), 16-26. Para 1532: Archivo Municipal de Gandía (AMG), Manuals de Consells (M.C), B-17, acta del 31-V-1532; para 1597: ibidem, Libro VII de Racional, B-452, fol 37; para 1601: ibidem, fol. 79 y para 1604: ibidem, Libro Judicial, B-1.876, fol. $176 \mathrm{r}^{\circ}$ (subrayado es nuestro).

(72).- Archivo Histórico Nacional, Sección Osuna, leg.: 1.203-2, nº 25 y 22 (protocolos del notario Bertomeu Deusa).

(73).- Ibidem, $\mathrm{n}^{\circ} 26$.

(74).- AMG, M.C., B-17 (acta del 15-XI-1535).

(75).- "Expulsió dels moriscos i creixement agrari al País Valencià", Afers- 5/6 (Homenatge al Dr. En Sebastià Garcia Martinez) (Catarroja, 1987), 273-316 (cit de p.: 274).

(76).- El azúcar es un monopolio señorial en todo su ciclo de producción, desde el reparto anual de planteles que hace el duque hasta los "ingenios" y "trapiches" que son regalías señoriales. Tiene, además, la peculiaridad de ser el único producto del que se exige partición aquí antes de 1609 , siendo ésta de un $50 \%$ de la cosecha de caña. Pero los beneficios que genera no repercuten sólo en las arcas ducales sino que llegan a muchos más (jornaleros y personal asalariado que trabajan en esas instalaciones, arrendatarios de "trapiches", comerciantes, "sucrers", proveedores de las formas de cerámica, etc...). Por lo demás, esa vinculación con la población morisca, es algo que nos parece evidente y que hemos explicado en El ducado de Gandía..., I, 248-278.

(77).- "La expulsión de Ios moriscos: su repercusión en la propiedad y la población en la zona de los riegos del Vernisa", Saitabi, X (1960), 81-100.

(78).- AMG, B-1.671 al B-1675.

(79).- Estructures agraries al sud..., I, 118.

(80).- Ibidem, I, 131 y 138.

(81).- "Los moriscos aragoneses..., 198.

(82).- Carta de D. Luis Fajardo al Rey, cit. en: F. CHACON: "El problema de la conviviencia..., 119 , nota 28 .

(83).- AHN. Osuna, leg.: 1,203-2, n² 25 (Protocolos del notario B. Deusa).

(84).- J. SERRANO: op cit., I, 259-262.

(85).- F. GARCIA-OLIVER: El monestir..., II, 558. En estas páginas abundan los ejemplos concretos que avalan la importancia que tenía aquí la ganadería, como, en general, otras actividades económicas desarrolladas por la población musulmana, demostrándose fehacientemente que la idea de una dedicación exlusiva al cultivo de un pequeño trozo de tierra, no se corresponde, ni mucho menos, con una realidad que era un poco más compleja. 
(86).- AHN. Osuna, leg.: 1.203-2, $\mathrm{n}^{\mathrm{2}} 25$ y 26 (Protocolos del notario B. Deusa).(87).- S.LA PARRA: El ducado de Gandía..., I, 114 y ss.

(88).- AHN. Osuna, leg:: 1.066-1.

(89).- "Cuentas del tendero morisco Gerónimo Hoix (Gandía, 1587)", Al-Qantara, III (1982), 135-171. La ubicación de la tienda -que la Dra. Labarta confiesa desconocer- es un dato interesante, pues ésa era una zona nueva, resultado del crecimiento que había experimentado el arrabal en los últimos 40 ó 50 años, lo que evidencia que el próspero negocio de este morisco no venía tampoco desde antiguo, sino que se había labrado en esos años (...es decir, desde el final de las Germanías a esta parte). Llama la atención, por lo demás, el que los precios de Hoix fueran mucho más bajos que los que da Hamilton para 1602, de manera que en una arroba de aceite, por ejemplo, la diferencia va desde los 210 dineros del uno a los 236 ' 1 que da el otro; en 12 pares de alpargatas, de 192 d. a 216 d.; en una libra de azafrán, de 759 a 771 '7 d.; en una libra de seda la diferencia es aún mucho mayor: $216 \mathrm{~d}$. frente a 834 dineros... (pp.: 156-157).

(90).- AMG. M.C., B-17, actas del: 19, 23, 25 y 29 de junio, 23 y 28 de julio y 11 de agosto de 1522 .

(91).- F. GARCIA-OLIVER: El monestir..., II, 585-586. No es èste un caso aislado: "A Miquel Puig, a Joan Molins, a Azmet Baia i al seu fill Elel, als Moferig, als Munder, als Florins i als Zignells acudeixen camperols d'escasa heretat per abastir-se de teles, cereals, préstecs monetaris i nodriments" (Ibidem, II, 588). Sobre las actividades financieras desempeñadas por moriscos, Cfr.: E.CISCAR: "Prestamistas moriscos en Valencia", Cuadernos de Historia, 5 (Madrid, 1975), 269-286.

(92).- F. GARCIA-OLIVER: El monestir..., II, 608.

(93).- Alvaro CASTILLO: "La coyuntura de la economía valenciana en los siglos XVI y XVII", Anuario de Historia Económica y Social, II (cit. por DOMINGUEZ ORTIZ-B.VINCENT: Historia de los moriscos..., 215) y E. CISCAR: Tierra y señorio en el País Valenciano (1570-1620), Del Cenia al Segura, Valencia, 1977, 153. Con menos fundamento, Joan Fuster los ha asimilado a una especie de esquiroles o traidores de clase por su relación con los titulares de señoríos (Nosaltres els valencians, Edicions 62, Barcelona, 1980, 6ª ed., 67).

(94).- "Historia de una represión..., 45-46. 